\title{
Genetically Targeted All-Optical Electrophysiology with a Transgenic Cre-Dependent Optopatch Mouse
}

\author{
Shan Lou, ${ }^{1}$ Yoav Adam, ${ }^{1}$ E Eli N. Weinstein, ${ }^{1,2}$ Erika Williams, ${ }^{3}$ Katherine Williams, ${ }^{1}$ Vicente Parot, ${ }^{1}$ \\ CNikita Kavokine, ${ }^{1}$ Stephen Liberles, ${ }^{3}$ Linda Madisen, ${ }^{4}$ Hongkui Zeng, ${ }^{4}$ and Adam E. Cohen ${ }^{1,2,5}$ \\ ${ }^{1}$ Department of Chemistry and Chemical Biology and ${ }^{2}$ Department of Physics, Harvard University, Cambridge, Massachusetts 02138, ${ }^{3}$ Department of Cell \\ Biology, Harvard Medical School, Boston, Massachusetts 02115, ${ }^{4}$ Allen Institute for Brain Science, Seattle, Washington 98107, and ${ }^{5} \mathrm{Howard} H u g h e s$ \\ Medical Institute, Chevy Chase, Maryland 20815
}

Recent advances in optogenetics have enabled simultaneous optical perturbation and optical readout of membrane potential in diverse cell types. Here, we develop and characterize a Cre-dependent transgenic Optopatch 2 mouse line that we call Floxopatch. The animals expressed a blue-shifted channelrhodopsin, CheRiff, and a near infrared Archaerhodopsin-derived voltage indicator, QuasAr2, via targeted knock-in at the rosa26 locus. In Optopatch-expressing animals, we tested for overall health, genetically targeted expression, and function of the optogenetic components. In offspring of Floxopatch mice crossed with a variety of Cre driver lines, we observed spontaneous and optically evoked activity in vitro in acute brain slices and in vivo in somatosensory ganglia. Cell-type-specific expression allowed classification and characterization of neuronal subtypes based on their firing patterns. The Floxopatch mouse line is a useful tool for fast and sensitive characterization of neural activity in genetically specified cell types in intact tissue.

Key words: optogenetics; optopatch; transgenic mice; voltage imaging

Significance Statement

Optical recordings of neural activity offer the promise of rapid and spatially resolved mapping of neural function. Calcium imaging has been widely applied in this mode, but is insensitive to the details of action potential waveforms and subthreshold events. Simultaneous optical perturbation and optical readout of single-cell electrical activity ("Optopatch") has been demonstrated in cultured neurons and in organotypic brain slices, but not in acute brain slices or in vivo. Here, we describe a transgenic mouse in which expression of Optopatch constructs is controlled by the Cre-recombinase enzyme. This animal enables fast and robust optical measurements of single-cell electrical excitability in acute brain slices and in somatosensory ganglia in vivo, opening the door to rapid optical mapping of neuronal excitability.

\section{Introduction}

Tools for optical stimulation (Boyden et al., 2005) and optical readout (Looger and Griesbeck, 2012) of neural activity in intact

Received May 15, 2016; revised Sept. 6, 2016; accepted Sept. 6, 2016.

Author contributions: S. Lou, Y.A., E.W., S. Liberles, L.M., H.Z., and A.E.C. designed research; S. Lou, Y.A., E.W., K.W., N.K., and L.M. performed research; E.W. and S. Liberles contributed unpublished reagents/analytic tools; S. Lou, E.N.W., V.P., L.M., H.Z., and A.E.C. analyzed data; S. Lou, E.N.W., and A.E.C. wrote the paper.

This work was supported by the Howard Hughes Medical Institute, the Allen Institute for Brain Science, and GlaxoSmithKline (Bioelectronic Medicines Initiative Grant). A.E.C. is supported by National Institutes of Health (NIH) Grant 1-R01-EB012498. Y.A. is supported by a long-term fellowship of the Human Frontier Science Program. E.W. is supported by NIH Grants F30CA177170 and T32GM007753. S. Liberles is supported by NIH Grant DK103703. We thank Vaibhav Joshi and Melinda Lee for technical assistance. We thank Qiufu Ma, Xinzhong Dong, Rohini Kuner, Venkatesh Murthy, and Paola Arlotta for scientific discussions and for sharing Cre driver mouse lines; Corey Smith, Stephen Lewis, and Paulina Getsy for training and assistance; the Harvard University Genome Modification Facility for technical support in generating transgenic mice; and the Harvard Center for Brain Sciences for providing confocal imaging facilities.

A.E.C. is a founder of Q-State Biosciences. The remaining authors declare no competing financial interests.

Correspondence should be addressed to Adam E. Cohen, Department of Chemistry and Chemical Biology, Harvard University, Mallinckrodt 115, 12 0xford Street, Cambridge, MA 02138. E-mail: cohen@chemistry.harvard.edu. tissues have individually provided fundamental insights into neuronal information processing. Pairing of optical stimulation and readout increases the power of both techniques because one can thereby probe input-output properties of defined cells or circuits, even while these are embedded in an extended network. Optogenetic stimulation allows one to explore neural behavior over a wider range of parameters and in a more systematic fashion than one can achieve through observation of spontaneous or sensory evoked activity alone. Knowledge of input-output properties of cells and microcircuits can then shed insight into observations of natural activity.

Several recent studies reported simultaneous two-photon optogenetic stimulation and two-photon calcium imaging in vivo (Rickgauer et al., 2014; Packer et al., 2015; Carrillo-Reid et al., 2016). Calcium imaging provides a low-pass-filtered surrogate 
for neuronal firing and can be challenging to apply in cell types that either fire very rapidly or have strongly buffered $\mathrm{Ca}^{2+} \mathrm{dy}-$ namics. Recently developed genetically encoded voltage indicators (GEVIs) have enabled voltage imaging in flies (Yang et al., 2016), in mice in vivo via viral expression (Gong et al., 2015), and over large cortical regions in a transgenic mouse (Madisen et al., 2015), but none of these reporters was spectrally compatible with optogenetic stimulation.

We showed previously that a combination of a blue-lightactivated channelrhodopsin (CheRiff) and a red-light-excited Archaerhodopsin-derived voltage indicator (QuasAr2) could be used for simultaneous all-optical electrophysiology in cultured neurons or organotypic brain slice cultures (Hochbaum et al., 2014). The actuator and reporter were coexpressed via a bicistronic vector that we called "Optopatch."

A key attraction of genetically encoded tools is the ability to target measurements to specified neuronal subtypes in intact tissue. Adeno-associated virus vectors can drive high expression in vivo, but typically show nonuniform expression that is highest near the site of injection and drops off over $\sim 300 \mu \mathrm{m}$. For quantitative optogenetic stimulation, one prefers uniform channelrhodopsin levels; otherwise, the proportionality between illumination intensity and photocurrent will vary between cells. Cre-dependent knock-in transgenes achieve uniform expression (Gong et al., 2007; Madisen et al., 2012; Harris et al., 2014) and have been used to make a wide variety of fluorescent reporter mice (Madisen et al., 2012, 2015; Zariwala et al., 2012).

Cre-dependent reporter mice are also useful as a source of explanted tissues and cells in which one may, for example, probe the physiology and pharmacology of genetically defined subsets of neurons in a higher throughput manner than can be achieved in intact tissues. Dorsal root ganglia (DRG) and other peripheral neurons are attractive targets for this approach due to their great genetic and functional diversity (Liu and Ma, 2011; Abraira and Ginty, 2013; Chiu et al., 2014; Usoskin et al., 2015). Furthermore, the physiology and patterns of gene expression of DRG neurons (and many other cell types) change while in culture (Zheng et al., 2007), so the ability to perform measurements on acutely dissociated cells is particularly important.

Here, we describe a Cre-dependent transgenic mouse containing the Optopatch2 construct for all-optical electrophysiology (Hochbaum et al., 2014). We characterize the effects of Optopatch2 expression on measures of whole-animal and neuronal health. We then demonstrate all-optical electrophysiology measurements in dissociated neurons, in acute brain slices, in the PNS in explanted nerves, and in vivo using a variety of Cre driver lines to target expression to different neuronal subtypes. Application in the CNS in vivo will require improvements in membrane localization and expression levels. As a facile and robust source of Optopatch-expressing tissues and cells, this mouse line promises to be a useful tool for optical electrophysiology.

\section{Materials and Methods}

Animal protocol. Animal protocols were approved by the Institutional Animal Care and Use Committee of Harvard University in accordance with National Institutes of Health guidelines.

Gene targeting in ES cells and generation of knock-in Cre-dependent reporter mice. The Optopatch gene (Hochbaum et al., 2014) and targeting vector (Madisen et al., 2012) were cloned from constructs described previously. Optopatch2, comprising QuasAr2-mOrange2(Y71A)-P2ACheRiff-eGFP, was inserted into a Rosa26-pCAG-LSL-WPRE-bGHpA targeting vector between the LSL and WPRE sequences. The LSL sequence contains loxP-stop codons-3x SV40 polyA-loxP as transcriptional terminator. The vector map is shown in Figure $1 A$. The targeting vector was tested in HEK293T cells (ATCC CRL-11268). The vector was delivered via TransIT-LT1 transfection reagent (Mirus MIR2306) either alone or with CAG-Cre vector (Addgene 13775). GFP expression was tested 3-4 d after the transfection.

Gene targeting was performed at the Allen Institute for Brain Science. The targeting vector was linearized and transfected into a mouse embryonic stem cell (ES) line (G4, derived from a 129/B6 F1 hybrid) for homologous recombination. G418-resistant ES clones were screened by PCR using primers spanning the $1.1 \mathrm{~kb} 5^{\prime}$ genomic arm (forward primer: $5^{\prime}$-gggctccggctcctcagaga- $3^{\prime}$, reverse primer: $5^{\prime}$-atgccaggcgggccatttac- $3^{\prime}$ ) and then confirmed by Southern blot (Madisen et al., 2012). ES clones were karyotyped and verified to be chromosomally normal. ES clone injection was performed at the Harvard University Genetic Modification Facility. Optopatch-positive ES clones were injected into C57BL/6J blastocysts to obtain chimeric mice. Chimeric mice were bred with C57BL/6J mice to obtain F1 Floxopatch ${ }^{+/-}$mice.

Genotyping was performed with the following PCR primer pairs: G1: 5'-GCTGGTCTCCAACTCCTAATC-3' and S12: 5'-CTGTATCTGG CTATGGCCG- $3^{\prime}$ to yield a $1.1 \mathrm{~kb}$ band from the Optopatch 2 transgene and GT5: 5'-CTT TAA GCC TGC CCA GAA GA-3' and GT8: 5' -TCC CAA AGT CGC TCT GAG TT-3' to yield a 242 bp band in the wild-type Rosa26 allele. In Floxopatch ${ }^{+/-}$mice, the GT5/GT8 pair yielded a $242 \mathrm{bp}$ band; in homozygous Floxopatch ${ }^{+/+}$mice, this band was absent (see Fig. $1 A$, inset).

Mapping patterns of Optopatch2 expression. Floxopatch mice were crossed with the following Cre driver lines: $\mathrm{Na}_{V} 1.8$-Cre (gift from Rohini Kuner via Qiufu Ma), MrgA3-Cre (gift from Xinzhong Dong via Qiufu $\mathrm{Ma})$, CaMKII-Cre (gift from Venkatesh Murthy), Parvalbumin-IRESCre (JAX \#008069), Somatostatin (SST)-IRES-Cre (JAX \#013044), and CAG-CreEr (JAX \#004682). Expression of the reporter genes was assessed by eGFP fluorescence in whole-mount DRG at postnatal day 30 (P30) and in sagittal brain sections at P14 stained with an anti-GFP antibody (primary antibody: rabbit anti-GFP, Abcam ab13970; secondary antibody: goat anti-rabbit 488, Abcam ab150077). Images were acquired on an Olympus FV 1000 confocal microscope at the Harvard Center for Brain Sciences microscope facility.

Monitoring health and weight of transgenic Floxopatch mice. Animals were housed at $23^{\circ} \mathrm{C}$ in a $12 \mathrm{~h}$ light/dark cycle. Three to five mice with shared genotype were housed per cage. Animals of both sexes were weighed on their weaning day (P21). Mice were observed for crude physical or behavioral abnormalities.

$D R G$ culture and transfection. All patch-clamp electrophysiology measurements were performed in dissociated DRG neurons dissected from T11-L6 of P14 male mice. Dissection and dissociation followed published protocols (Malin et al., 2007). Acutely dissociated DRG neurons were plated at a density of $1500 \mathrm{cells} / \mathrm{cm}^{2}$ on glass coverslip-bottomed imaging chambers (MatTek) precoated with poly-D-lysine (PDL; SigmaAldrich P7405) and Matrigel (BD Biosciences 356234). Cells were incubated with complete media I (1:1 DMEM and F12, Thermo-Fisher $11320-033 ; 10 \%$ FBS, Life Technologies $10082-147)$ at $37^{\circ} \mathrm{C}$ with $5 \% \mathrm{CO}_{2}$ overnight. Cells were measured 1-3 d after dissociation.

For measurements with transient expression, the Floxopatch targeting vector was electroporated into dissociated $\mathrm{Na}_{V} 1.8-\mathrm{Cre}^{+1-}$ male mouse DRG neurons using a Lonza 4D X electroporator following manufacturer protocol DR114 with the P3 primary cell kit (Lonza V4XP-3032). Electroporated neurons were plated at a density of $1500 \mathrm{cells} / \mathrm{cm}^{2}$, but cell death led to a lower final density. Neurons were then cultured in complete media I for the first $2 \mathrm{~d}$ and thereafter in neurobasal medium (ThermoFisher 21103-049).

Nodose ganglia preparation and imaging. For imaging of nodose ganglia ex vivo, the nodose and petrosal ganglia complex was dissected bilaterally from a $\mathrm{Na}_{V} 1.8$ - $\mathrm{Cre}^{+/-}$;Floxopatch ${ }^{+/-}$double heterozygous P14 male mouse following a published protocol (Qiao et al., 2003). The dissected ganglion was placed in a $35 \mathrm{~mm}$ dish treated with PDL and Matrigel and incubated in complete media $\mathrm{I}$ for $2 \mathrm{~h}$ at $37^{\circ} \mathrm{C}$ and $5 \% \mathrm{CO}_{2}$.

For nodose ganglia imaging in vivo, $\mathrm{Na}_{V} 1.8$-Cre $^{+/-}$; Floxopatch ${ }^{+/+}$ P58 male mice were anesthetized by continuous inhalation of isoflurane (1-3\%). Anesthesia was assessed every hour by toe pinch. When under deep anesthesia as assessed by toe pinch, the mouse was placed on a 
microscope stage and body temperature maintained at $37^{\circ} \mathrm{C}$ with a feedback body control system composed of rectal probe (WPI RET-3) and animal temperature controller (WPI ATC2000). The neck and the abdomen were shaved and sterilized. A midline neck incision was made, and the nodose ganglion stabilized for imaging. Details of the surgical preparation have been described previously (Williams et al., 2016). The duration of the surgery was typically $1-1.5 \mathrm{~h}$. The ganglion was then imaged with a $60 \times$ water-immersion objective, numerical aperture 1.0 , in a home-built microscope. The preparation was stable for up to $6 \mathrm{~h}$ of imaging. Sequential optical recordings from single neurons proceeded at a rate of $\sim 15$ cells $/ \mathrm{h}$. After experiments, the mouse was killed by overdose of isoflurane.

Brain slice preparation. Acute brain slices were prepared from P15-P21 male and female mice. The mice were deeply anesthetized by intraperitoneal injection of $90 \mathrm{mg} / \mathrm{kg}$ ketamine and $10 \mathrm{mg} / \mathrm{kg}$ xylazine and then perfused with carbogen $\left(95 \% \mathrm{O}_{2}, 5 \% \mathrm{CO}_{2}\right)$-saturated ice-cold slicing solution with the following composition (in $\mathrm{mM}$ ): 110 choline chloride, $2.5 \mathrm{KCl}, 1.25 \mathrm{NaH}_{2} \mathrm{PO}_{4}, 25 \mathrm{NaHCO}_{3}, 25$ glucose, $0.5 \mathrm{CaCl}_{2}, 7 \mathrm{MgCl}_{2}$, 11.6 Na-ascorbate, and 3.1 Na-pyruvate. Mice were then decapitated and the brains were removed into ice-cold slicing solution and then rapidly blocked for coronal sectioning at $300 \mu \mathrm{m}$ thickness on a vibratome (Leica VT 1200S). Slices were then incubated for $45 \mathrm{~min}$ at $34^{\circ} \mathrm{C}$ in a carbogenated artificial CSF (ACSF) with the following composition (in mM): 127 $\mathrm{NaCl}, 2.5 \mathrm{KCl}, 1.25 \mathrm{NaH}_{2} \mathrm{PO}_{4}, 25 \mathrm{NaHCO}_{3}, 25$ glucose, $2 \mathrm{CaCl}_{2}$, and 1 $\mathrm{MgCl}_{2}$. Slices could be used for $4-6 \mathrm{~h}$ after harvest. The osmolarity of all solutions was adjusted to $300-310 \mathrm{mOsm}$ and the $\mathrm{pH}$ was maintained at $\sim 7.3$ under constant bubbling with carbogen.

Electrophysiology. All simultaneous Optopatch and electrophysiology measurements were performed in extracellular medium containing the following (in mM): $125 \mathrm{NaCl}, 2 \mathrm{KCl}, 2 \mathrm{CaCl}_{2}, 1.5 \mathrm{MgCl}_{2}, 15 \mathrm{HEPES}$, and 30 glucose, adjusted to $\mathrm{pH} 7.3$ with $\mathrm{NaOH}$ and to $305-310$ mOsm with sucrose. Filamented glass micropipettes (WPI) were pulled to a tip resistance of 5-10 $\mathrm{M} \Omega$ and filled with internal solution containing the following (in mM): 125 potassium gluconate, $8 \mathrm{NaCl}, 0.6 \mathrm{MgCl}_{2}, 0.1 \mathrm{CaCl}_{2}, 1$ EGTA, 10 HEPES, $4 \mathrm{Mg}$-ATP, and $0.4 \mathrm{Na}$-GTP, adjusted to pH 7.3 with $\mathrm{NaOH}$ to $295 \mathrm{mOsm}$ with sucrose. Pipettes were positioned with a Sutter MP285 manipulator. Whole-cell, voltage-clamp, and current-clamp recordings were acquired using a patch-clamp amplifier (A-M Systems 2400), filtered at $5 \mathrm{kHz}$ with the internal filter, and digitized with a National Instruments PCIE-6323 acquisition board at $10 \mathrm{kHz}$. Data were acquired only from DRG neurons with access resistance $<25 \mathrm{M} \Omega$ and with membrane resistance $>10$-fold greater than access resistance. Wildtype control mice were selected from littermates of the $\mathrm{Na}_{V} 1.8-\mathrm{Cre}^{+/-}$; Floxopatch $^{+/-}$mice. All experiments were performed in parallel at the same experimental conditions. To avoid spurious excitation of CheRiff, experiments were performed in dim light.

Optopatch imaging. Experiments on cultured neurons and in vitro nodose ganglia were conducted on home-built inverted epifluorescence microscopes described previously (Kralj et al., 2012; Hochbaum et al., 2014; Zou et al., 2014). Experiments on acute brain slices and in vivo nodose ganglia were performed on a home-built upright microscope. Acute slices were perfused continuously with ACSF at $\sim 2 \mathrm{~mL} / \mathrm{min}$. In a typical experimental run, images of eGFP and QuasAr2 fluorescence were first acquired at full field of view. Data were then acquired with an sCMOS camera (Hamamatsu Orca Flash 4.0) at frame rate of 500 frames/s, using a limited region of interest to achieve the high frame rate. Cumulative red light exposure was typically limited to $<15$ s per neuron. The optical conditions used in each experiment are listed in Table 1.

Data analysis and statistics. All plotted error bars represent SEM except where indicated. For two-sample comparisons of a single variable, data were tested for normality using the D'Agostino and Pearson Omnibus test and Shapiro-Wilk test. If the data were detectably non-Gaussian, a nonparametric Mann-Whitney test was performed. Otherwise, a twotailed $t$ test was performed. Animal weight multiway comparisons were made using a one-way ANOVA with Kruskal-Wallis test using wild-type as a reference.

Fluorescence image and movie analysis. Fluorescence values were extracted from raw movies in two ways. One approach used the maximumlikelihood pixel-weighting algorithm described previously (Kralj et al.,
Table 1. Optical conditions

\begin{tabular}{lcclll}
\hline Figure & $\begin{array}{l}\text { Red } \\
\text { intensity } \\
\left(\mathrm{W} / \mathrm{cm}^{2}\right)\end{array}$ & $\begin{array}{l}\text { Blue } \\
\text { intensity } \\
\left(\mathrm{mW} / \mathrm{cm}^{2}\right)\end{array}$ & $\begin{array}{l}\text { Field } \\
\text { of view } \\
\left(\mu \mathrm{m}^{2}\right)\end{array}$ & $\begin{array}{l}\text { Objective } \\
\text { lens }\end{array}$ & $\begin{array}{l}\text { Magnification } \\
\text { at camera }\end{array}$ \\
\hline Fig. 3A & 600 & 0 & 7500 & $60 \times$ & $30 \times$ \\
Fig. 3B,C & 600 & $50-200$ & 7500 & $60 \times$ & $30 \times$ \\
Fig. 4A,B,D & 600 & $600-3000$ & 7500 & $60 \times$ & $30 \times$ \\
Fig. 5 & 800 & $50-350$ & 3600 & $20 \times$ & $20 \times$ \\
Fig. 6 & 800 & $200-350$ & 3600 & $20 \times$ & $20 \times$ \\
Fig. 7A,B & 300 & $600-3000$ & 7500 & $60 \times$ & $30 \times$ \\
Fig.7C & 2500 & 500 & 1200 & $60 \times$ & $60 \times$ \\
Fig. 7D & 2500 & $300-500$ & 1200 & $60 \times$ & $60 \times$ \\
\hline
\end{tabular}

The $60 \times$ objective was an Olympus LUMPlanFLN and the $20 \times$ objective was an Olympus XLUMPlanFLN, both with a numerical aperture of 1.00 .

2012). Briefly, the fluorescence at each pixel was correlated with the whole-field average fluorescence. Pixels that showed stronger correlation to the mean were weighted preferentially. This algorithm automatically found the pixels carrying the most information and deemphasized background pixels. Alternatively, a user manually defined a region comprising the cell body and calculated fluorescence from the unweighted mean of pixel values within this region. Both approaches gave similar results. For calculations of $\Delta F / F$, background fluorescence from a cell-free region was subtracted from the baseline fluorescence of the cell.

Automatic image segmentation. Multiple $\mathrm{CaMKII}^{+}$neurons often overlapped in the field of view and were challenging to separate morphologically. We used an automated segmentation algorithm to extract the fluorescence dynamics of the individual cells based on their distinct temporal dynamics. Our fundamental assumption was that different cells spiked at different times, so clusters of pixels that covaried synchronously were associated to the same cell. Briefly, movies were first median filtered in space to remove spatially uncorrelated (and therefore likely noisy) fluctuations. With each $500 \mathrm{~ms}$ stimulus, cells all showed similar rises in baseline, but were distinguishable by their individually unique firing patterns. We therefore performed high-pass filtering in time using a Gaussian filter (window size $20 \mathrm{~ms}$, SD $3 \mathrm{~ms}$ ). Next, we performed principle components analysis (PCA) on the time-domain pixel covariance matrix to reduce the dimensionality of the dataset. We then used timedomain independent component analysis (ICA) to produce a filter that mapped collections of pixels to individual cells.

As an additional noise reduction strategy, spatial filters were cleaned using morphological dilation to remove isolated pixels that were separate from the main body of the cell (the structuring element was a disk of diameter 2 pixels). ICA produced fluorescence traces with a shape that was scaled and offset from the underlying $\Delta F / F$ that would have been recorded from an isolated cell. To extract real $\Delta F / F$ values, we first used automatic thresholding to identify regions of each cell that did not overlap with any other cell. Pixels within this region were weighted according to how well they fit the ICA trace and their weighted average trace served as a (noisy) signal with appropriate $\Delta F / F$. The ICA-derived trace was then scaled to match the reference trace with a linear fit.

We also extracted an image of each cell by calculating the correlation between the high-pass-filtered trace and each pixel of the high-passfiltered movie. The distribution of correlation values comprised Poissondistributed background noise, with a long tail corresponding to the cell. We set a dynamic threshold of 1.8 times the estimated Poisson parameter $\lambda$ to determine which pixels were most likely to be on-cell.

ICA produces an arbitrary number of potential cells. We set the maximum possible number of cells to six and then further eliminated traces that did not correspond to cells based on the following criteria. First, cells had to exhibit higher fluorescence during stimulation than after it (this is a common ICA failure mode). Second, cells had to have at least five spikes during the entire stimulus protocol. Finally, cells had to be morphologically contiguous and compact; we performed morphological opening with a disk of diameter 6 pixels and discarded "cells" that lost $75 \%$ or more of their area after this procedure. Manual verification ensured that the automatic image segmentation gave reasonable images of cells and corresponding intensity traces. 
$\mathrm{SST}^{+}$neurons were more sparsely distributed than $\mathrm{CaMKII}^{+}$cells. We did not observe more than one $S S T^{+}$cell in a single field of view. In general, these cells also showed a lower QuasAr2 expression level. To extract fluorescence signals, we used a modified version of the maximum likelihood algorithm described in Kralj et al. (2012). Movies were first temporally high-pass filtered to remove baseline changes in fluorescence. Pixels were initially weighted according to the ratio $\sigma_{\text {on }} / \sigma_{\text {off }}$, where $\sigma_{\text {on }}$ and $\sigma_{\text {off }}$ are the SDs of the (high-pass filtered) fluorescence while the blue light was turned on or off, respectively. This ratio formed a spatial mask that was then normalized and multiplied by the temporally highpass-filtered movie to extract a first estimate of the cell's voltage dynamics. Next, we calculated which pixels matched this estimate well according to the maximum likelihood estimate algorithm in Kralj et al. (2012). This procedure provided a spatial mask that, when applied to the original unfiltered movie, gave the cell's fluorescence trace. We computed an image of the cell in the same way as in the ICA case, setting a threshold on the correlation between each high-pass-filtered pixel and the high-pass-filtered final trace. For consistency with the ICA analysis, we eliminated inactive "cells" with fewer than five action potentials.

Photobleaching correction and spike finding. We estimated the photobleaching baseline using a sliding minimum filter with a window of $1 \mathrm{~s}$ (longer than our stimulus pulses of $500 \mathrm{~ms}$ ). The fluorescence signal was divided by this photobleaching estimate at each time point to obtain a $\Delta F / F$ trace. We used a percentile filter to approximate the baseline fluorescence around each action potential. The filter identified those points in a sliding window (10 frames, $20 \mathrm{~ms}$ long) at the 40th percentile and assigned them baseline status. At points not assigned to the baseline, the local baseline value was inferred via linear interpolation. Signal height was then measured relative to this baseline.

For data from acute brain slices, we used a dynamic thresholding algorithm to robustly identify spikes despite variations in signal-to-noise ratio (SNR) between cells. The algorithm was built on two assumptions. First, spikes were above the noise floor of the recording. Second, within a single cell and single stimulus interval, spikes were presumed to all be of approximately similar amplitude. First, we estimated the noise level, $\sigma$, of each recording by median filtering each trace with a window size of 400 $\mathrm{ms}$ to remove baseline offsets, and then taking the difference between the $50^{\text {th }}$ and $16^{\text {th }}$ percentiles. We set an initial threshold at $3 \sigma$ above mean. This threshold gave a collection of potential spikes, but possibly some false-positives. Next, we estimated the spike height by taking the 90th percentile of the spike heights. This high percentile calculation provided a robust measure of spike height, even in the presence of many falsepositives (which tended to have heights close to the threshold). Our final spike threshold was $50 \%$ of this estimated spike height (as long as this threshold was greater than the initial threshold). This dynamic thresholding was used in all cases regardless of neuron type. The algorithm identified spikes that were consistent with visual examination of the traces.

Estimating CheRiff expression level. In each field of view, we recorded a static image of eGFP fluorescence to quantify the level of CheRiff-eGFP. We found the average eGFP expression in regions of each cell that did not overlap with any other cell. We used the correlation between the highpass-filtered spiking trace and the high-pass-filtered QuasAr2 movie to calculate a geometrical correction factor for each region of the cell that accounted for variation of membrane orientation with respect to the camera. The average eGFP fluorescence in the nonoverlapping region was multiplied by the geometric correction to give an estimate of the CheRiff expression per unit membrane. Because CaMKII cells and SST cells were analyzed differently, our estimates of which pixels were on-cell may be slightly different, so we did not compare expression between the two cell lines. Instead, we quantified single-cell expression relative to the mean of each subtype separately.

\section{Results}

\section{Generation and verification of Floxopatch mouse line}

We produced a transgenic mouse containing Cre-dependent Optopatch2 in the Rosa26 locus (JAX Strain 28678, B6N.CgGt(ROSA)26Sor ${ }^{\text {tm1Acoh} / J ; ~ F i g . ~ 1 A) . ~ G e n o t y p i n g ~ o f ~ F l o x o p a t c h ~}{ }^{+/-}$ and Floxopatch ${ }^{+/+}$mice confirmed transgene insertion (Fig. $1 A$, inset). We found previously that the presence of a fluorescent protein fused to the voltage indicator QuasAr2 facilitated trafficking to the plasma membrane. We wanted to preserve the green/yellow part of the spectrum for other uses, so we introduced the Y71A mutation into the mOrange2 fused to QuasAr2. This mutation rendered the mOrange2 nonfluorescent (Shaner et al., 2008), but preserved its beneficial effects on trafficking. We maintained an eGFP expression marker on the CheRiff (CheRiffeGFP) to facilitate identification of expressing cells. The Optopatch2 construct (Hochbaum et al., 2014), the insertion locus (Madisen et al., 2012), and the method of making the mouse (Madisen et al., 2012) have been described previously. We call the floxed Optopatch mouse "Floxopatch" or Ai130.

To test for tissue-specific expression in vivo, Floxopatch mice were crossed with a variety of Cre driver lines. For the CNS, we used CAG-CreEr, CaMKII-Cre, SST-Cre, and Parvalbumin $(P V)$-Cre. Histology showed patterns of eGFP fluorescence matching expression patterns reported in the Allen Brain Atlas (Fig. 1B; Madisen et al., 2010; Harris et al., 2014). In the absence of a Cre driver, confocal images of brain slices from Floxopatch $^{+/+}$mice were indistinguishable from slices from Floxopatch $^{-1-}$ mice, confirming absence of leaky expression. Examination at cellular resolution revealed that each Cre line drove expression in cells with distinct locations and morphology. eGFP fluorescence (indicating localization of CheRiff) showed expression in the soma membrane and throughout the dendritic arbor (Fig. 1B, bottom). To test expression in the PNS, we crossed the Floxopatch mouse with drivers for $\mathrm{Na}_{V} 1.8$-Cre, $\mathrm{MrgA3}$-Cre, $S S T$-Cre, and PV-Cre. Examination of DRG neurons showed expression in approximately the anticipated proportion of neurons for each of these drivers (Fig. 1C) (Price, 1985; Agarwal et al., 2004; Zacharová and Palecek, 2009; Han et al., 2012).

We then tested the effects of Optopatch2 expression on physiological and neuronal health. Floxopatch mice crossed with neuron subtype-specific Cre drivers had normal weight at weaning (P21; Fig. 2A) and were visually indistinguishable from their wild-type siblings. In animals aged 8-11 months, we performed a pooled comparison of Optopatch2-expressing mice under a variety of Cre drivers (Emx1-Cre, CaMKII-Cre, SST-Cre, or $\mathrm{Na}_{V}$ 1.8-Cre) to nonexpressing controls. The Optopatch2expressing animals showed no obvious differences in appearance or behavior and had normal body weights for their age (female controls, $26.5 \pm 2.1 \mathrm{~g}, n=4$; females expressing Optopatch2, $29.1 \pm 4.9$ g, $n=6$ across multiple Cre drivers; male controls, $34.4 \pm 7.3 \mathrm{~g}, n=9$; males expressing Optopatch2, $33.2 \pm 8.6 \mathrm{~g}$, $n=3$ across multiple Cre drivers).

Previous measurements by manual patch clamp found no significant difference in electrical properties of dissociated hippocampal neurons transiently transfected with Optopatch2 compared with controls (Hochbaum et al., 2014). We studied the effects of Optopatch2 expression in dissociated wild-type, Floxopatch $^{+1-}, \mathrm{Na}_{V}$ 1.8-Cre ${ }^{+/-}$;Floxopatch ${ }^{+/-}$, and $\mathrm{Na}_{V} 1.8$-Cre ${ }^{+/-}$; Floxopatch $^{+1+}$ DRG sensory neurons (P14-P18 mice, 2-3 d in vitro, DIV). We found no significant difference in membrane resistance (Fig. 2B), membrane capacitance (Fig. 2C), resting potential (Fig. 2D), or threshold currents (Fig. 2E) compared with wild-type control neurons. Numbers and statistics are given in Table 2 .

\section{Characterization of Floxopatch mouse peripheral neurons in vitro}

Next, we tested the function of the Optopatch constructs in dissociated $\mathrm{Na}_{V} 1.8$-Cre ${ }^{+/-}$; Floxopatch ${ }^{+1-}$ DRG sensory neurons. 


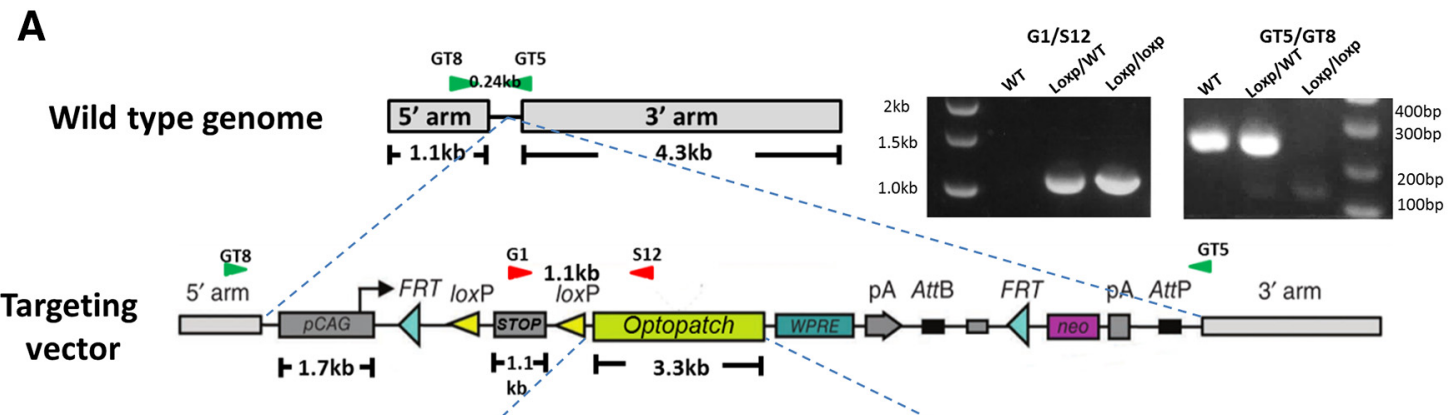

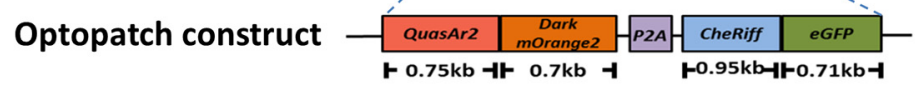

B
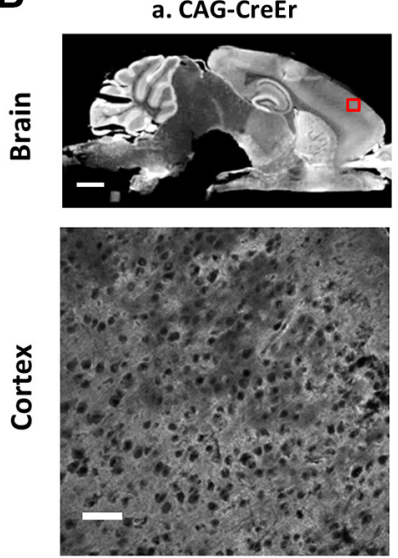

C

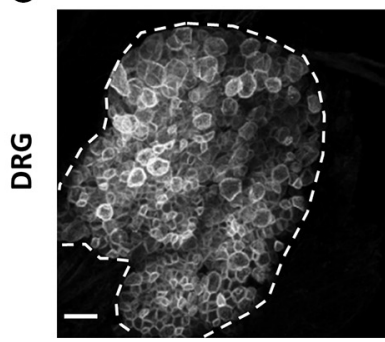

b. CaMKII-Cre
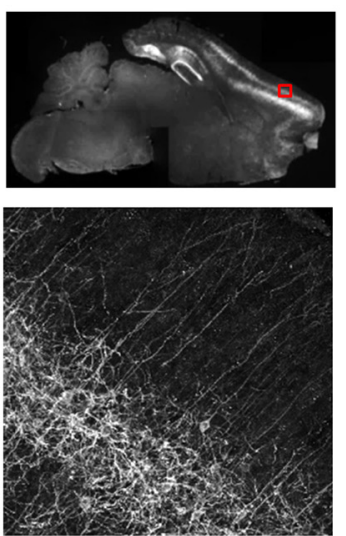

b. MrgprA3-Cre

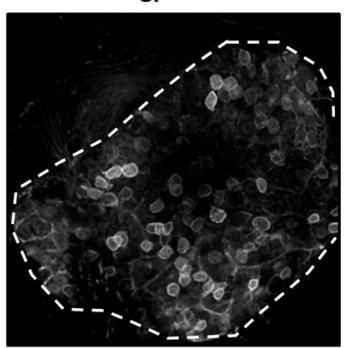

c. Somatostatin-Cre
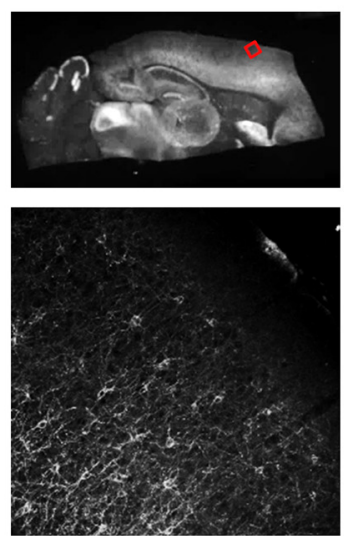

c. Somatostatin-Cre



d. Parvalbumin-Cre
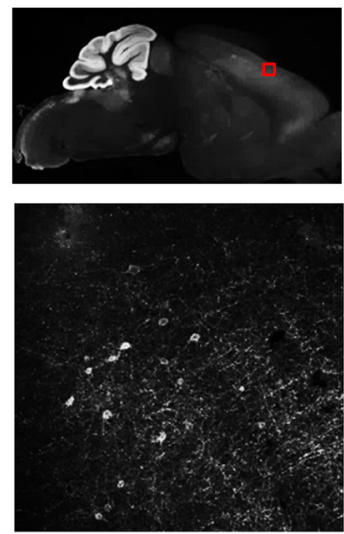

d. Parvalbumin-Cre

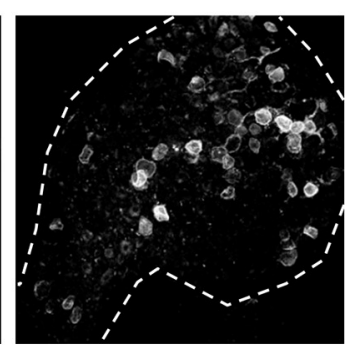

Figure 1. Cre-dependent 0ptopatch2 transgenic mice show cell-type-specific expression. $A$, Schematic of the genomic recombination site (top), the Optopatch targeting vector (middle), and the Optopatch construct (bottom). Green arrows indicate the primer sites for distinguishing homozygous from heterozygous mice. The insert comprised CAG::IoxP-Stop-loxP-0ptopatch2-WPRE. CAG is a strong universal promoter (Niwa et al., 1991). The loxP-Stop-loxP cassette is a transcriptional stop motif that can be excised by the Cre recombinase. The Optopatch2 construct comprised QuasAr2-dark m0range2-P2A-CheRiff-eGFP. QuasAr2 is a genetically encoded near infrared voltage indicator, P2A is a self-cleaving ribosome skip sequence (Hochbaum et al., 2014), CheRiff is a blue-shifted channelrhodopsin variant, and eGFP is a fluorescent expression marker for CheRiff. WPRE is the woodchuck hepatitis virus posttranscriptional regulatory element (Madisen et al., 2012; Hochbaum et al., 2014). Red arrows indicate primer sites for detection of the Optopatch sequence. Inset, Genotyping results using G1/S12 showed $1.1 \mathrm{~kb}$ bands in Floxopatch ${ }^{+/-}$and Floxopatch $^{+/+}$genomic DNA, but not in Floxopatch ${ }^{-/-}$DNA. Genotyping results using GT5/GT8 showed 242 bp bands in Floxopatch ${ }^{-/-}$and Floxopatch $^{+/-}$genomic DNA, but not in Floxopatch ${ }^{+/+}$ DNA. B, Genetically targeted Optopatch expression in the CNS. Top, Sagittal sections of Floxopatch mouse brains with different Cre drivers. Confocal fluorescence images show distribution of CheRiff-eGFP. Red squares indicate the cortical area magnified in the bottom. Scale bar, $1 \mathrm{~mm}$. Bottom, Confocal fluorescence images showing cellular structures. Scale bar, $50 \mu \mathrm{m}$. C, Genetically targeted Optopatch2 expression in DRG. Images show maximum projections of confocal z-stacks of CheRiff-eGFP fluorescence. Scale bar, $50 \mu \mathrm{m}$.

eGFP fluorescence, indicating localization of CheRiff, showed excellent membrane labeling. QuasAr2 fluorescence showed a mixture of membrane labeling and intracellular puncta (Fig. $3 A, B)$. We measured membrane voltage via whole-cell patch clamp and simultaneously recorded movies of QuasAr2 fluorescence at $500 \mathrm{frames} / \mathrm{s}\left(\lambda_{\mathrm{exc}}=640 \mathrm{~nm}, \lambda_{\mathrm{em}}=667-742 \mathrm{~nm}\right)$. Upon acute addition of capsaicin $(1 \mu \mathrm{M})$, we observed close correspondence of optical and electrical signals both for spikes and subthreshold events (Fig. 3A).

We then stimulated a cell with $500 \mathrm{~ms}$ pulses of blue light of increasing intensity and recorded the response via simultaneous whole-cell patch clamp and QuasAr2 fluorescence. Cells showed spontaneous and optically evoked firing, with clearly resolved action potentials and close correspondence of optical and electrical signals (Fig. 3B). The fluorescence amplitude for a single action potential was $3.3 \pm 1.6 \% \Delta F / F$ (mean $\pm \mathrm{SD}, n=26$ cells, raw whole-cell fluorescence), corresponding to an SNR (spike height relative to baseline noise) of $26 \pm 13$ (mean \pm SD).

We tested the capability of the Optopatch construct to report faithful action potential waveforms from different DRG subtypes in vitro. In $\mathrm{Na}_{V} 1.8^{+}$or $\mathrm{MrgA3}^{+}$neurons, action potential waveforms showed good concordance with patch-clamp recordings 
A

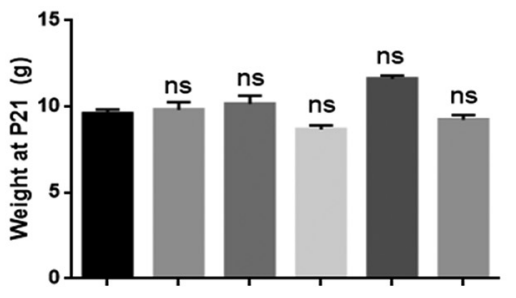

$\begin{array}{lllllll}\text { Floxopatch } & -/- & +/- & +/- & +/+ & +/- & +/+ \\ \mathrm{Na}_{1} 1.8-\mathrm{Cr} \text { - } & -/- & -/- & -/- & -/- & +/- & +/- \\ \text { CamKII-Cre } & -/- & -/- & +/- & +/- & -/- & -/-\end{array}$
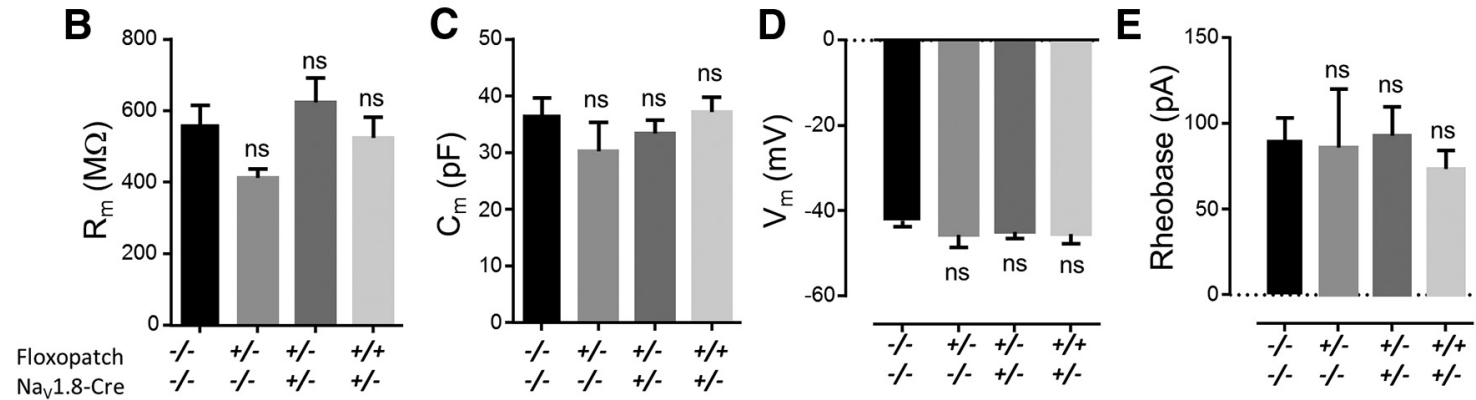

Figure 2. Tests for physiological effects of transgenic Optopatch2 expression. $\boldsymbol{A}$, Weight comparison among Floxopatch-expressing mice and controls at weaning (P21). $\boldsymbol{B}$-E, Comparison of electrophysiological parameters in control and 0ptopatch2-expressing neurons from transgenic mice.

Table 2. Effect of Optopatch expression in transgenic mice

\begin{tabular}{|c|c|c|c|}
\hline & Average & SEM & No. \\
\hline \multicolumn{4}{|l|}{ Weight (g) } \\
\hline WT & 9.6 & 0.3 & 33 \\
\hline Ai130 het & 9.8 & 0.5 & 12 \\
\hline CamKII-Cre;Ai130 het & 10.2 & 0.5 & 4 \\
\hline CamKII-Cre;Ai130 homo & 8.7 & 0.2 & 8 \\
\hline $\mathrm{Na}_{\mathrm{v}} 1.8-\mathrm{Cre} ; \mathrm{Ai} 130$ het & 11.6 & 0.2 & 4 \\
\hline $\mathrm{Na}_{\mathrm{v}} 1.8-\mathrm{Cre} ; \mathrm{Ai} 130$ homo & 9.2 & 0.3 & 15 \\
\hline \multicolumn{4}{|l|}{$R_{\mathrm{m}}(\mathrm{M} \Omega)$} \\
\hline WT & 561.5 & 54.7 & 19 \\
\hline Ai130 het & 414.6 & 22.1 & 8 \\
\hline $\mathrm{Na}_{\mathrm{V}} 1.8-\mathrm{Cre} ; \mathrm{Ai} 130$ het & 623.4 & 69.5 & 25 \\
\hline $\mathrm{Na}_{\mathrm{v}} 1.8-\mathrm{Cre} ; \mathrm{Ai} 130$ homo & 525.7 & 57.6 & 15 \\
\hline \multicolumn{4}{|l|}{ Capacitance (pF) } \\
\hline WT & 36.7 & 3.0 & 19 \\
\hline Ai130 het & 30.4 & 5.0 & 8 \\
\hline $\mathrm{Na}_{\mathrm{V}} 1.8-\mathrm{Cre} ; \mathrm{Ai} 130$ het & 33.5 & 2.4 & 25 \\
\hline $\mathrm{Na}_{v} 1.8-\mathrm{Cre} ; \mathrm{Ai130}$ homo & 37.3 & 2.6 & 15 \\
\hline \multicolumn{4}{|l|}{ Resting potential (mV) } \\
\hline WT & -42.3 & 1.5 & 18 \\
\hline Ai130 het & -45.5 & 2.9 & 8 \\
\hline $\mathrm{Na}_{\mathrm{V}} 1.8-\mathrm{Cre} ; \mathrm{Ai} 130$ het & -44.9 & 1.6 & 15 \\
\hline $\mathrm{Na}_{\mathrm{v}} 1.8-\mathrm{Cre} ; \mathrm{Ai} 130$ homo & -45.4 & 2.2 & 14 \\
\hline \multicolumn{4}{|l|}{ Rheobase (pA) } \\
\hline WT & 90.0 & 13.4 & 24 \\
\hline Ai130 het & 86.3 & 33.6 & 8 \\
\hline $\mathrm{Na}_{\mathrm{V}} 1.8-\mathrm{Cre} ; \mathrm{Ai} 130$ het & 92.9 & 16.8 & 34 \\
\hline $\mathrm{Na}_{v} 1.8-$ Cre;Ai130 homo & 73.3 & 10.8 & 15 \\
\hline
\end{tabular}

Here, Ai130 refers to the Floxopatch genotype. There were no significant differences in body weight or in electrophysiological parameters between mice with or without 0 ptopatch expression driven by neuron-specific promoters.

for overall action potential width and shape of the afterhyperpolarziation (Fig. 3C,D). Spikes in $N a_{V} 1.8^{+}$neurons have a characteristic shoulder (Stansfeld and Wallis, 1985) that appeared clearly in patch-clamp recordings sampled at $5 \mathrm{kHz}$ (Fig. $3 \mathrm{~A}$, right), but not when the patch-clamp signal was downsampled to $500 \mathrm{~Hz}$ nor in the optical recording at $500 \mathrm{~Hz}$ (Fig. 3C, left). SST ${ }^{+}$ neurons showed extremely narrow action potentials as measured by manual patch clamp (full-width at half-maximum $1.41 \pm 0.28$ $\mathrm{ms}$, mean $\pm \mathrm{SD}, n=4$ cells). The $1.3 \mathrm{~ms}$ response time of QuasAr2 at $25^{\circ} \mathrm{C}$, combined with the $2 \mathrm{~ms}$ exposure time of the camera, led to low-pass filtering of the fluorescence signal for these spikes (Fig. $3 C, D$ ). Optically recorded spike amplitudes in SST cells were smaller $(\sim 1 \% \Delta F / F)$ than in other neuronal types (e.g., $3.3 \% \Delta F / F$ for $\mathrm{Na}_{\mathrm{V}} 1.8$-positive neurons). Therefore, improvements in speed of reporters and detection systems are still needed to record detailed spike shape properties and from the fastestspiking interneurons.

Optical recording provides a degree of spatial resolution not attainable with electrode-based recordings, so we explored the possibility of subcellular and simultaneous multicellular recordings. At $60 \times$ magnification, optically induced and optically detected action potentials were detectable in single neurites (Fig. $4 A)$. Using a microscope with a larger field of view $(150 \times 100$ $\mu \mathrm{m}$; see Materials and Methods), we optically stimulated and optically recorded from multiple cultured neurons simultaneously (Fig. 4B). Image segmentation using PCA/ICA resolved spiking from up to 11 individual cells simultaneously (see Materials and Methods and Mukamel et al., 2009).

A potential merit of transgenic expression is improved uniformity of expression relative to other gene delivery methods. Variation in expression of a voltage indicator is of little concern because measurements are typically reported as $\Delta F / F$, a parameter that is insensitive to absolute expression. Variation in expression of an optogenetic actuator, however, leads to variation in photocurrent for a given illumination intensity and thereby to apparent cell-to-cell variation in neuronal firing properties.

We compared DRG neurons derived from P14 $\mathrm{Na}_{V} 1.8-\mathrm{Cre}^{+/-}$; Floxopatch ${ }^{+1-}$ mice and neurons derived from P14 $\mathrm{Na}_{V} 1.8$ $\mathrm{Cre}^{+/-}$;Floxopatch ${ }^{-1-}$ littermates electroporated with the Floxopatch construct at DIV1. Both were measured at DIV7, with simultaneous Optopatch and manual patch-clamp measurements (Fig. 4C,D). Photocurrent densities in electroporated cells were higher but more variable than in transgenic cells $(4.4 \pm 3.5$ 



Figure 3. Optopatch measurements in cultured DRG neurons derived from Floxopatch mice. $A$, Simultaneous fluorescence (red) and manual patch clamp (black) recordings during perfusion with $1 \mu$ m capsaicin of a cultured DRG neuron derived from a Nav $1.8-\mathrm{Cre}^{+/-}$; Floxopatch ${ }^{+/-}$mouse $\left(\lambda_{\text {exc }}=640 \mathrm{~nm}, 600 \mathrm{~W} / \mathrm{cm}^{2}, \lambda_{\text {em }}=667-742 \mathrm{~nm}\right)$. Close-ups of the boxed regions are shown to the right of each trace. $\boldsymbol{B}$, Left, Epifluorescence images of a cultured DRG neuron derived from a $\mathrm{Na}_{v} 1.8-\mathrm{Cre}^{+/-}$; Floxopatch ${ }^{+/-}$mouse. Scale bar, $5 \mu \mathrm{m}$. Middle, simultaneous fluorescence (red) and manual patch clamp (black) recordings with optogenetic stimulation. The cell was stimulated with steps of blue light $\left(\lambda_{\text {exc }}=488 \mathrm{~nm}, 500 \mathrm{~ms}\right.$ duration, $\left.50-200 \mathrm{~mW} / \mathrm{cm}^{2}\right)$ and fluorescence of QuasAr2 was recorded $\left(\lambda_{\text {exc }}=640 \mathrm{~nm}, 600 \mathrm{~W} / \mathrm{cm}^{2}, \lambda_{\text {em }}=667-742 \mathrm{~nm}\right)$. Right, Close-up of the boxed region showing correspondence of the optical and electrical signals. C, Optically evoked action potentials were recorded simultaneously via QuasAr2 fluorescence sampled at $500 \mathrm{~Hz}$ and manual patch-clamp electrophysiology in current-clamp mode $(i=0)$ sampled at $10 \mathrm{kHz}$. Signals were aligned by spike peak and averaged to calculate a mean action potential waveform. Electrical traces were down-sampled to $500 \mathrm{~Hz}$. Mean action potential waveforms in DRG neurons are shown. Left, $\mathrm{Na}_{\mathrm{V}} 1.8-\mathrm{Cre}^{+/-}$; Floxoptach ${ }^{+/-}$mice $\left(n=17\right.$ cells). Middle, MrgA3-Cre ${ }^{+/-}$; Floxopatch ${ }^{+/-}$mice $\left(n=5\right.$ cells). Right, SST-Cre ${ }^{+/-}$; Floxopatch ${ }^{+/-}$mice $(n=3$ cells). Shading indicates SEM. D, Comparison of optically and electrically recorded action potential widths (full-width at half-maximum). Spike widths in SST ${ }^{+}$neurons were too narrow to be well resolved in the optical measurements.

$\mathrm{pA} / \mathrm{pF}$ vs $2.8 \pm 0.7 \mathrm{pA} / \mathrm{pF}$, mean $\pm \mathrm{SD}, n=6$ electroporated cells, $n=11$ transgenic cells). The coefficients of variation (SD/mean) were $80 \%$ in electroporated cells and $25 \%$ in transgenic cells. The threshold intensity for a $5 \mathrm{~ms}$ blue flash to trigger a spike was lower, but more variable, in electroporated cells than in transgenic cells $\left(270 \pm 260 \mathrm{~mW} / \mathrm{cm}^{2}\right.$ vs $1020 \pm 240 \mathrm{~mW} / \mathrm{cm}^{2}$, mean \pm $\mathrm{SD}, n=30$ electroporated cells, $n=29$ transgenic cells). The coefficients of variation were $96 \%$ in electroporated cells and $24 \%$ in transgenic cells. Therefore, in the transgenic cells, im- proved homogeneity of expression translated into more uniform measurements of firing properties.

We explored the possibility of obtaining higher expression in the homozygous Floxopatch ${ }^{+/+}$mouse. In $\mathrm{Na}_{V} 1.8-\mathrm{Cre}^{+/-}$; Floxopatch ${ }^{+/+}$DRG neurons, the blue light threshold for triggering spikes was $36 \%$ lower than in $\mathrm{Na}_{V} 1.8$-Cre ${ }^{+/-}$; Floxopatch $^{+/-}$neurons (Floxopatch ${ }^{+/-}$: $0.22 \pm 0.034$ $\mathrm{W} / \mathrm{cm}^{2}, n=29$ cells, Floxopatch ${ }^{+/+}: 0.14 \pm 0.008 \mathrm{~W} / \mathrm{cm}^{2}$, $n=106$ cells, mean \pm SD, $p=0.0031$, two-tailed Mann-Whitney 
A

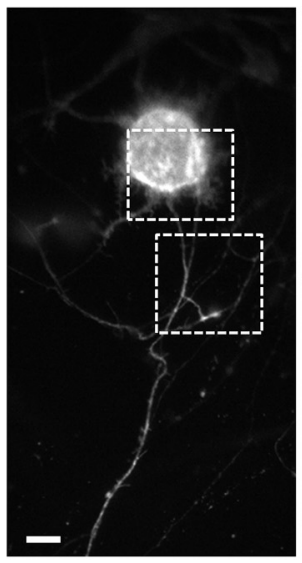

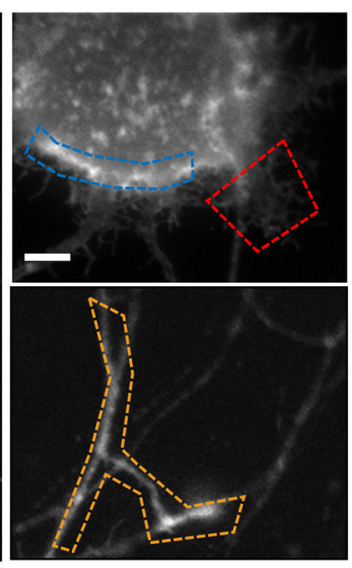

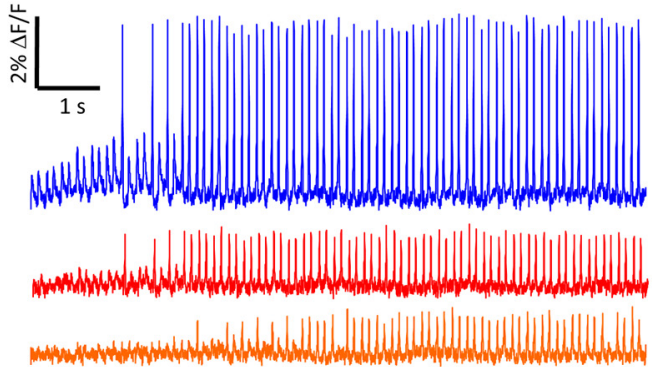

Stimulus

B

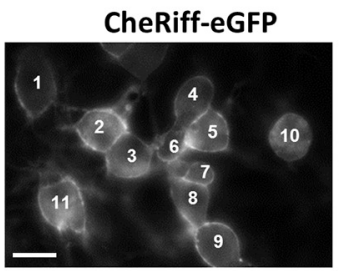

QuasAr2
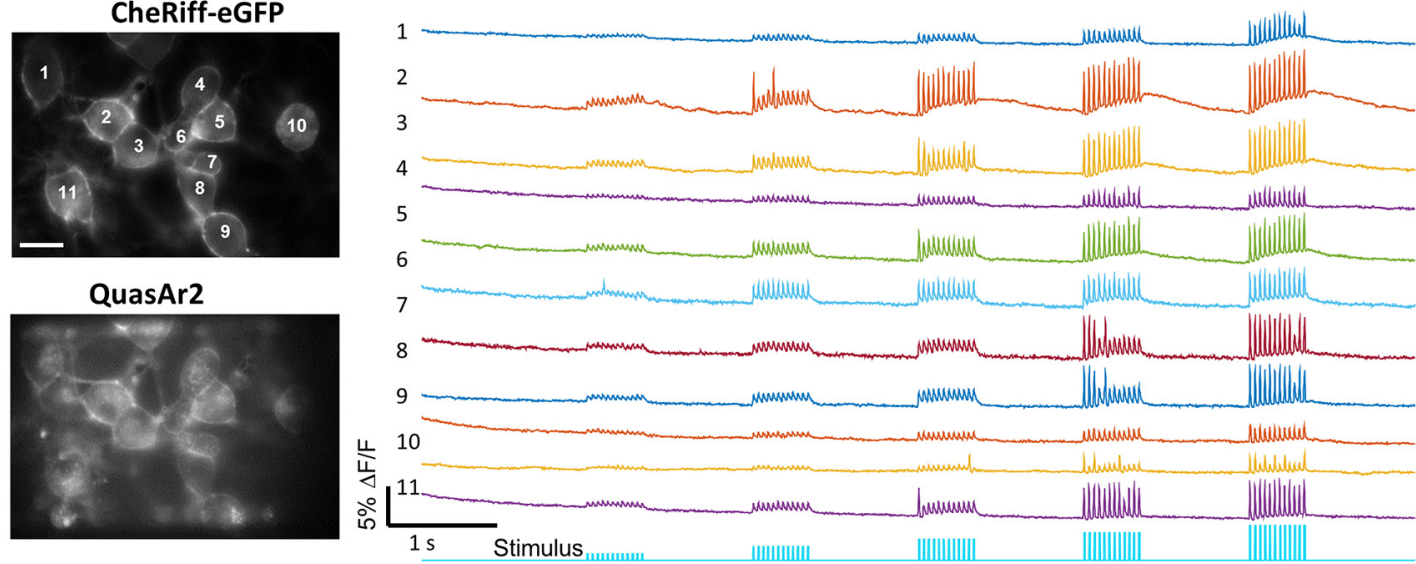

C
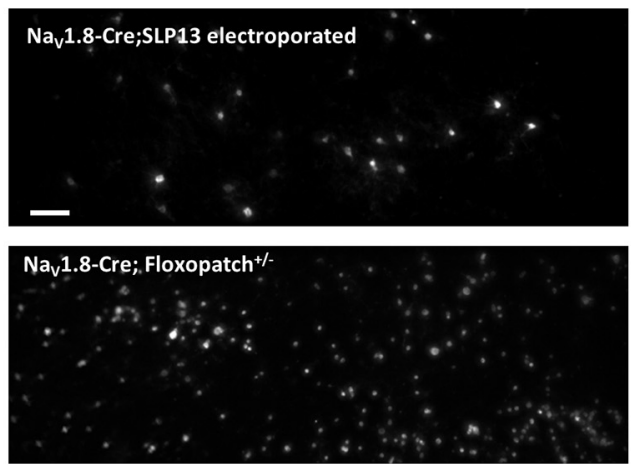

D
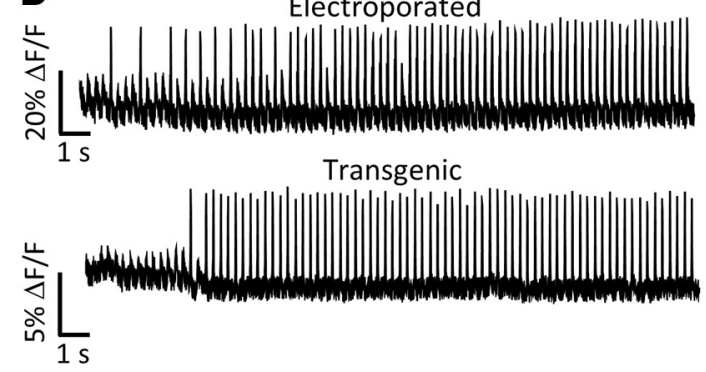

Stimulus

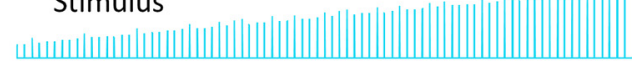

Figure 4. Optopatch recordings with subcellular and multicellular resolution. $A$, Subcellular recordings of action potentials in a cultured DRG neuron derived from a CAG-CreEr ${ }^{+/-}$; Floxopatch $^{+/-}$mouse after tamoxifen treatment. Left, Epifluorescence image of CheRiff-eGFP showing the whole cell. Scale bar, $10 \mu \mathrm{m}$. Middle, Close-up images of the boxed regions. Scale bar, $4 \mu \mathrm{m}$. Right, QuasAr2 fluorescence from the whole soma (blue) and the two colored regions indicated in the images. Stimulus: $\lambda_{\text {exc }}=488 \mathrm{~nm}, 10 \mathrm{~ms}$ pulses, repeated at $10 \mathrm{~Hz}$, increasing from 600 $\mathrm{mW} / \mathrm{cm}^{2}$ to $3 \mathrm{~W} / \mathrm{cm}^{2}$ in increments of $60 \mathrm{~mW} / \mathrm{cm}^{2}$. QuasAr2 fluorescence excited at $600 \mathrm{~W} / \mathrm{cm}^{2}$. B. Wide-field simultaneous Optopatch recording from 11 cultured DRG neurons from a $\mathrm{Na}_{V} 1.8-\mathrm{Cre}^{+/-}$;Floxopatch ${ }^{+1-}$ mouse. Left, Images of CheRiff-eGFP and QuasAr2 fluorescence. Scale bar, $20 \mu \mathrm{m}$. Right, Cells were stimulated with bursts of blue light, $2 \mathrm{~ms}$ pulses, repeated at $40 \mathrm{~Hz}$, for $0.5 \mathrm{~s}$, followed by $1 \mathrm{~s}$ rest, increasing intensity from $600 \mathrm{~mW} / \mathrm{cm}^{2}$ to $3 \mathrm{~W} / \mathrm{cm}^{2}$. QuasAr2 fluorescence excited at $600 \mathrm{~W} / \mathrm{cm}^{2}$. C, Comparison of eGFP fluorescence in cultured DRG neurons with Cre-dependent Optopatch2 expressed either via electroporation (top) or from a transgenic mouse (bottom). In both cases, neurons were derived from Na 1 1.8-Cre ${ }^{+/-}$mice and were cultured for $7 \mathrm{~d}$ after dissection. Scale bar, $100 \mu \mathrm{m}$. D, Measurements of optically induced spiking thresholds in electroporated or transgenic neurons. Stimulus protocol (bottom) and fluorescence traces (top). Excitability threshold was defined as the lowest light intensity that induced an action potential. Cells were stimulated with flashes of blue light, $5 \mathrm{~ms}$ on, $95 \mathrm{~ms}$ off, linearly increasing intensity from $600 \mathrm{~mW} / \mathrm{cm}^{2}$ to $3 \mathrm{~W} / \mathrm{cm}^{2}$ in increments of $60 \mathrm{~mW} / \mathrm{cm}^{2}$.

test) and the SNR of spikes in QuasAr2 fluorescence was approximately twice as high (Floxopatch ${ }^{+/-}: 12.6 \pm 0.8, n=53$ cells, Floxopatch $^{+/+}: 26.5 \pm 1.3, n=151$ cells, mean $\pm \mathrm{SD}, p<0.0001$, twotailed Mann-Whitney test). However, due to the greater demands of breeding homozygous Floxopatch mice, subsequent experiments were performed with heterozygotes.
Functional phenotyping in acute brain slice

The low brightness of rhodopsin-based reporters is a potential concern for imaging in intact tissue, where background autofluorescence is anticipated to be higher than in vitro. We quantified the autofluorescence of acute brain slice tissue from a P49 mouse under excitation at either $488 \mathrm{~nm}(520-540 \mathrm{~nm}$ emission) or 640 
nm (667-742 nm emission). This mouse did not express any fluorescent transgenes. An iris in an optical image plane in the illumination path ensured that the illumination areas and geometries were precisely matched for blue and red excitation. We made measurements at $n=21$ locations in cortical layers $2-5$ at a variety of illumination intensities in each color. Mean autofluorescence counts were $136 \pm 86$-fold higher (mean \pm SD) under blue excitation than under red excitation of the same intensity. Most point-to-point variability in autofluorescence occurred in the blue channel.

Encouraged by the low tissue autofluorescence under red excitation, we compared the signal-to-background ratio of eGFP fluorescence and QuasAr2 fluorescence in single neurons from a sparsely expressing CaMKII-Cre ${ }^{+/-}$; Floxopatch $^{+/-}$mouse. The mean signal-to-background ratio (cell membrane: neighboring tissue) was $1.7 \pm 0.26$ for QuasAr2 and $1.6 \pm 0.15$ for eGFP (mean $\pm \mathrm{SD}, n=23$ cells). Therefore, the lower brightness of QuasAr2 relative to eGFP was compensated by lower background autofluorescence under red illumination than under blue illumination. We used whole-cell manual patch clamp to record membrane voltage and simultaneously recorded QuasAr2 fluorescence while stimulating with pulses of current injection (200 pA, $10 \mathrm{~ms}$ duration, $5 \mathrm{~Hz}$ ). Single action potentials were clearly resolved in both optical and electrical recordings.

We next investigated whether Optopatch measurements could resolve differences in optically evoked firing patterns between genetically distinct neuronal subtypes in acute slices. We compared $\mathrm{CaMKII}^{+}$excitatory neurons (Dragatsis and Zeitlin, 2000) and $S S T^{+}$inhibitory neurons (Ma et al., 2006). CaMKIIdriven expression was too sparse for imaging before P16 and too dense for single-cell imaging after P21. We used animals at P19P20. At this age, Optopatch expression was primarily found in granule cells in the dentate gyrus of the hippocampus and in some pyramidal cells in layers 2 and 4 of the cortex (Dragatsis and Zeitlin, 2000). Data here are from the dentate gyrus. Due to the density of CaMKII-positive neurons, a single field of view often contained multiple overlapping cells. We used automated image segmentation based on time-domain ICA to resolve the firing patterns of individual neurons (see Materials and Methods). SSTdriven expression was stable after P14. For SST ${ }^{+}$neurons, we used animals at P15-P16. Expression was primarily in interneurons in the cortex and hippocampus (Urban-Ciecko et al., 2015). Data here are from the cortex. SST ${ }^{+}$neurons were sufficiently sparse as to not overlap in the field of view.

Cells were stimulated with an optical rheobase protocol comprising steps of blue light of $500 \mathrm{~ms}$ duration, of increasing intensity, with simultaneous monitoring of QuasAr2 fluorescence via red excitation and near infrared emission. Slice protocol, optical parameters, and image segmentation are described in the Materials and Methods. Single-cell firing patterns were clearly resolved, with an SNR of $8.5 \pm 2.6$ (mean \pm SD, $n=160$ cells; Fig. $5 A-D)$. Measurements proceeded at a rate of $\sim 30$ cells $/ \mathrm{h}$, with $\sim 85 \%$ of the time devoted to identifying and focusing on cells. We recorded from $101 \mathrm{CaMKII}^{+}$single cells in seven slices from three mice and $59 \mathrm{SST}^{+}$single cells in nine slices from four mice. Spikes were identified in fluorescence traces using an adaptive thresholding algorithm (see Materials and Methods). Fluorescent sources that either did not spike or spiked with an SNR $<3$ where discarded. The mean depth of optically recorded cells was 50-75 $\mu \mathrm{m}$ and most optically recorded cells were within $150 \mu \mathrm{m}$ of the slice surface (94\% for CaMKII, 97\% for SST), consistent with the $\sim 100 \mu \mathrm{m}$ optical scattering length of brain tissue at $640 \mathrm{~nm}$ (Yaroslavsky et al., 2002). Within the top $150 \mu \mathrm{m}$ of the slice, we did not observe depth-dependent differences in SNR or action potential properties, but few spiking cells were recorded within the top $40 \mu \mathrm{m}$, likely due to damage during slicing.

We observed significant differences in the firing patterns between $\mathrm{CaMKII}^{+}$and SST ${ }^{+}$neurons. SST ${ }^{+}$neurons had higher spontaneous activity than $\mathrm{CaMKII}^{+}(1.21 \pm 2.76 \mathrm{~Hz}$ in SST vs $0.35 \pm 0.40 \mathrm{~Hz}$ in CaMKII, mean $\pm \mathrm{SD}, p=3.0 \times 10^{-4}$, MannWhitney test; Fig. $5 B, D)$. Further, $\mathrm{SST}^{+}$neurons achieved higher maximum firing rates overall and at each stimulus intensity (16.9 \pm 5.7 action potentials per stimulus in SST vs $11.6 \pm 3.8$ in CaMKII, mean $\pm \mathrm{SD}, p=1.0 \times 10^{-8}$, unpaired two-sided $t$ test; Fig. $5 E, F)$. Although it is conceivable that the difference in optically induced firing rate is partially due to differences in channelrhodopsin expression, we also observed systematic differences in intrastimulus spike timing, which cannot be explained by differences in optogenetic drive. We quantified adaptation during each stimulus epoch as the average ratio between successive interspike intervals, $\left\langle\frac{\text { ISI }_{\mathrm{n}+1}}{\mathrm{ISI}_{\mathrm{n}}}\right\rangle$, where ISI $\mathrm{n}_{\mathrm{n}}=t_{n+1}-t_{n}$ is the time difference between the $n^{\text {th }}$ and $n+1^{\text {th }}$ spike. CaMKII ${ }^{+}$neurons showed significantly higher adaptation ratios $(1.9 \pm 1.2$ in CaMKII vs $1.2 \pm 0.3$ in SST, mean \pm SD, $p=2.5 \times 10^{-9}$, Mann-Whitney test; Fig. $5 G$ ). Differences in firing rate adaptation were enough to distinguish the two cell types, with a receiver operating characteristic area of 0.88 (Fig. $5 G$, inset). These population-level differences are consistent with manual patch-clamp measurements published for the same promoters (Gentet et al., 2012; Kowalski et al., 2016; Markram et al., 2015).

To test the feasibility of long-term Optopatch measurements in acute slices, we studied the behavior of neurons from CaMKII$\mathrm{Cre}^{+/-}$;Floxopatch ${ }^{+/-}$mice under either intermittent or continuous measurement conditions. First, we recorded from a cell once per minute for $20 \mathrm{~min}$. For each recording, we illuminated the cell for $500 \mathrm{~ms}$ with red light $\left(2500 \mathrm{~W} / \mathrm{cm}^{2}\right)$ and exposed it to 8 pulses of blue light of $10 \mathrm{~ms}$ duration, $20 \mathrm{~Hz}, 50 \mathrm{~mW} / \mathrm{cm}^{2}$. We then repeated this experiment, leaving the red laser on continuously for the whole $20 \mathrm{~min}$. Figure $5 \mathrm{H}$ shows that, under intermittent imaging, the Optopatch recording maintained long-term stability. Indeed, one of the merits of optical recording relative to patch clamp is that one can easily return to the same cell after long intervals. Under continuous monitoring, however, the fluorescence photobleached, diminishing to $30 \%$ of its initial amplitude after 20 min. Remarkably, we did not observe evidence of phototoxicity; that is, the cell continued to spike faithfully throughout the measurement.

Finally, Optopatch measurements enabled qualitative classification of neurons into more refined categories on the basis of their firing patterns or e-types (Markram et al., 2015). Figure 6 shows examples of this diversity of spontaneous and evoked activity in $\mathrm{CaMKII}^{+}$and $\mathrm{SST}^{+}$neurons. Among the $\mathrm{CaMKII}^{+}$ neurons, $\sim 60 \%$ showed a continuous accommodating pattern and $\sim 20 \%$ showed a delayed bursting pattern. Only $16 \%$ had spontaneous activity. Among the $\mathrm{SST}^{+}$neurons, $\sim 40 \%$ showed a continuous, nonaccommodating e-type and $\sim 40 \%$ showed a continuous, accommodating e-type. Approximately $37 \%$ had spontaneous activity. Our experimental conditions differed from published large-scale patch-clamp surveys (Markram et al., 2015; van Aerde and Feldmeyer, 2015) in one or more critical parameters (species, age of animal, brain region, method of specifying neuronal subpopulation), precluding a detailed comparison. We anticipate that the capacity for rapid and robust e-typing of genetically defined neurons in intact tissue may prove useful in 
A CamKII-Cre+/-; Floxopatch $+/-$

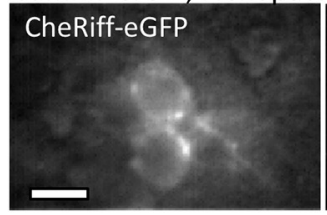

\section{QuasAr2}
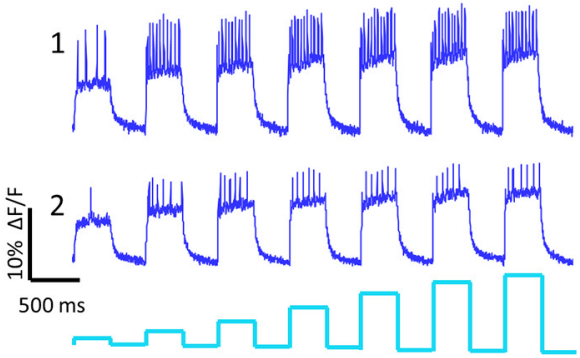

C Somatostatin-Cre ${ }^{+-} ;$Floxopatch $^{+-}$


B


$\mathbf{F}$
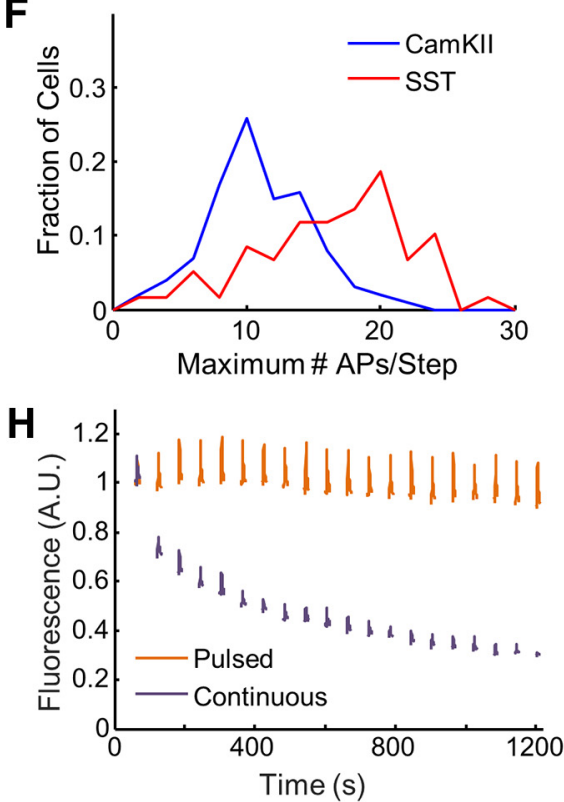

Figure 5. Optopatch recordings of neuronal excitability in acute brain slice. $A$, Top, Epifluorescence images of the Optopatch components in CaMKII ${ }^{+}$neurons in the dentate gyrus of the hippocampus. Scale bar, $10 \mu \mathrm{m}$. Bottom, Fluorescence of QuasAr2 in the indicated cells in response to illumination with steps of blue light of increasing intensity from 50 to $350 \mathrm{~mW} / \mathrm{cm}^{2}$. QuasAr2 fluorescence excited at $40 \mathrm{~mW}$ power $\left(800 \mathrm{~W} / \mathrm{cm}^{2}\right) \cdot \boldsymbol{B}$, Raster plot showing the spiking patterns of 101 neurons under a nine-step stimulation protocol. C, Top, Epifluorescence images of a SST ${ }^{+}$ inhibitory neuron in the cortex. Scale bar, $10 \mu \mathrm{m}$. Bottom, Fluorescence of QuasAr2 and the optical stimulus pattern. Optical parameters are as in $A$. D, Raster plot showing the spiking patterns of $59 \mathrm{SST}^{+}$neurons stimulated with the same protocol as in $\boldsymbol{B}$. E, Comparison of time-dependent spike rates of CaMKII ${ }^{+}$and $\mathrm{SST}^{+}$neurons under the same stimulus protocol. $\boldsymbol{F}$, Distributions of

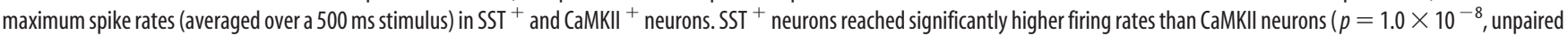
two-sided $t$ test). G Distributions of adaptation ratios (averaged over all stimulus strengths) in SST ${ }^{+}$and CaMKII ${ }^{+}$neurons. More SST ${ }^{+}$neurons than CaMKII ${ }^{+}$neurons were slow adapting (the populations were significantly different by the Mann-Whitney test, $p=2.5 \times 10^{-9}$ ). Inset, Receiver operating characteristic curve for separating CaMKII ${ }^{+}$neurons from SST ${ }^{+}$neurons based only on average adaptation ratio (area under the curve $=0.88$ ). $\boldsymbol{H}$, Optopatch measurements of neuronal stability under chronic measurement conditions. Orange indicates optically evoked and optically recorded spiking recorded with a $500 \mathrm{~ms}$ red illumination once per minute. Purple indicates optically evoked and optically recorded spiking with continuous red laser illumination. In both cases, the red laser illumination intensity was $2500 \mathrm{~W} / \mathrm{cm}^{2}$. 
A

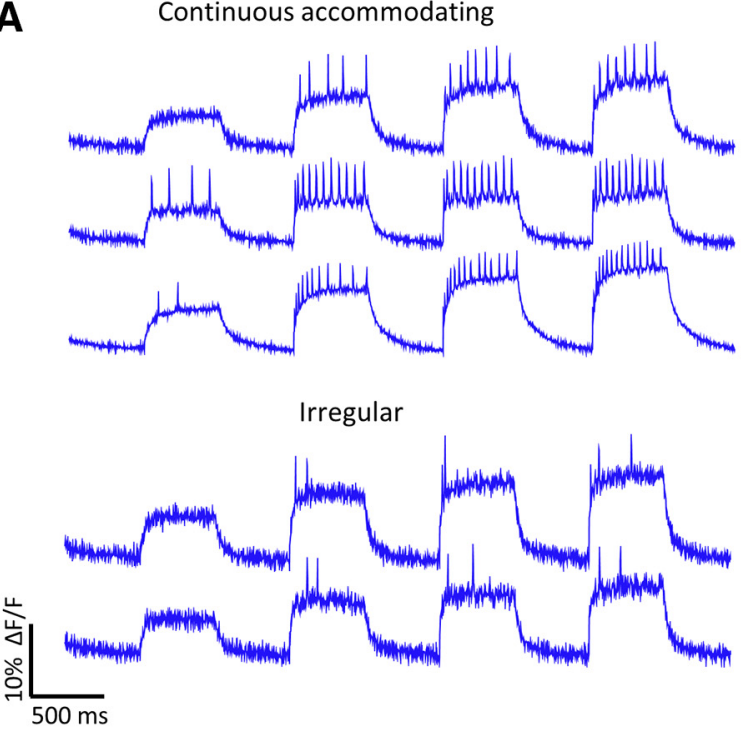

B

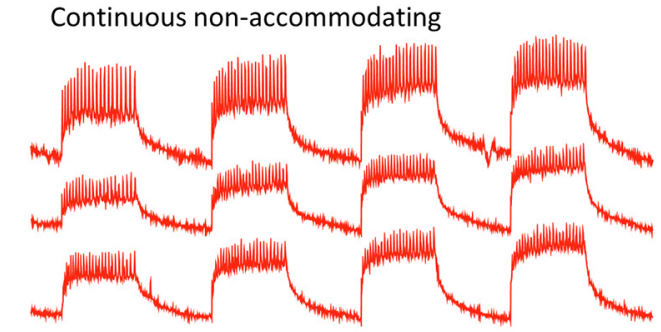

Continuous accommodating

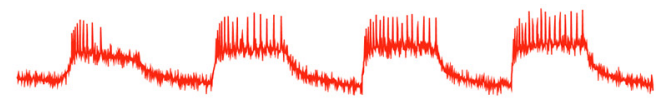

Continuous stuttering
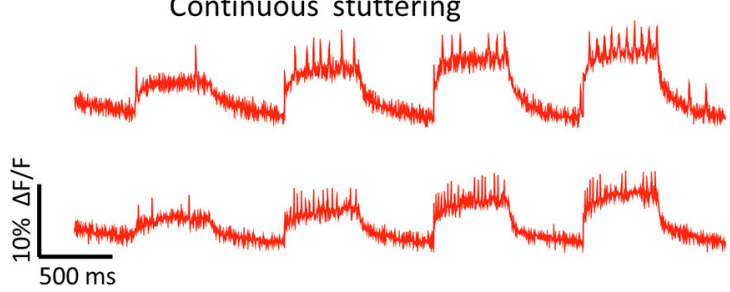

Burst accommodating

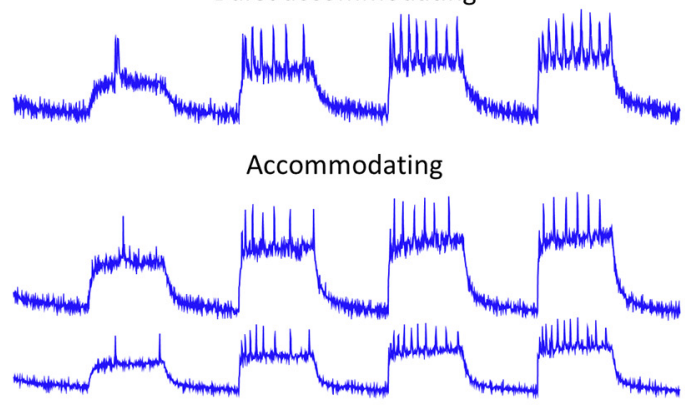

Depolarization block

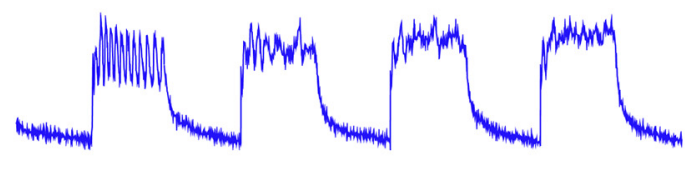



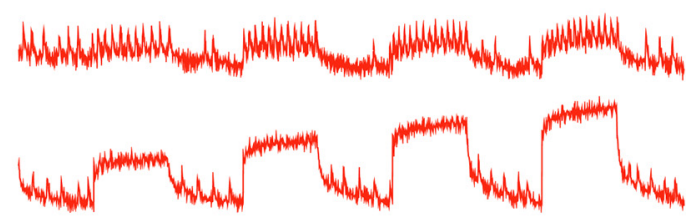

Figure 6. Electrophysiological diversity of optically probed neurons in acute brain slices. Classifications are qualitative descriptors of firing patterns, motivated by the scheme of Markram et al. (2015). $\boldsymbol{A}$, Firing patterns of CaMKII ${ }^{+}$hippocampal granule cells under step stimulation ( $500 \mathrm{~ms}$ on, $500 \mathrm{~ms}$ off) at blue intensities increasing from 200 to $350 \mathrm{~mW} / \mathrm{cm}^{2}$. B, Firing patterns of $S S T^{+}$ cortical interneurons stimulated as in $\boldsymbol{A}$.

efforts to extend these surveys to more brain regions and to more experimental conditions (Markram et al., 2015).

\section{Peripheral nerve imaging in vivo}

We then attempted Optopatch measurements in the Floxopatch mouse in vivo. We focused on peripheral nerves due to their good optical accessibility, limited vascularization, and the technical difficulties associated with studying these cells by manual patchclamp techniques. Neurons of the vagus nerve provide autonomic feedback from visceral organs including heart, lung, and digestive tract, and comprise mechanosensors, osmosensors, chemosensors, thermosensors, and nociceptors (Berthoud and Neuhuber, 2000). In mice, the cell bodies of sensory fibers in the vagus nerve reside in the jugular/petrosal/nodose ganglia (JPNG) complex. The JPNG is $1-2 \mathrm{~mm}$ in diameter and mostly translucent, with few capillaries and little fat or pigment. Recently developed surgical techniques have enabled optical access to the nodose ganglia in vivo (Williams et al., 2016).

$N a_{V} 1.8$-Cre drove expression of Optopatch 2 in $~ 75 \%$ of neurons in the nodose ganglia (Stirling et al., 2005; Gautron et al., 2011). First, we imaged explanted intact ganglia. Neuron cell bodies were densely packed (Fig. 7A), so we could record from up to 23 neurons simultaneously. Under optical stimulation with pulses of blue light of increasing intensity, we observed a wide variety of single-cell firing patterns (Fig. 7A). Most of the neurons were fast adapting, but several showed intermediate and slowly adapting firing patterns. It has been reported that some neurons in the nodose ganglia express P2X and are sensitive to ATP (Coc- 
A
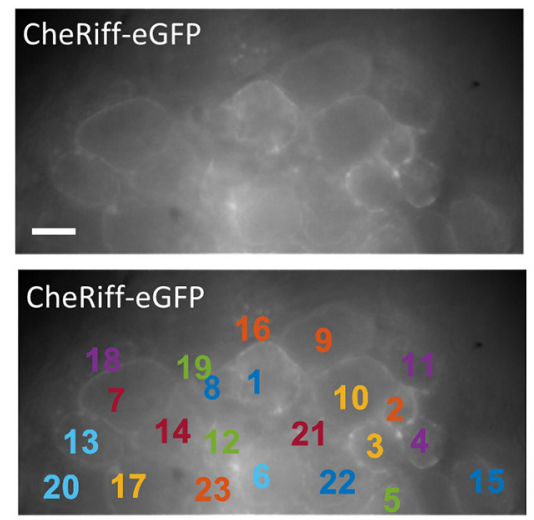

B



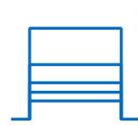
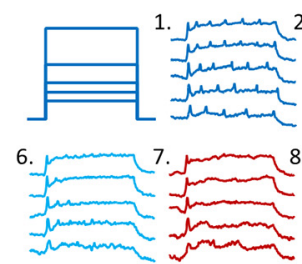

8.

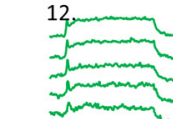

13

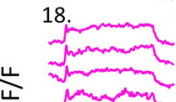

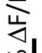

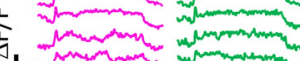

ㅇํำ
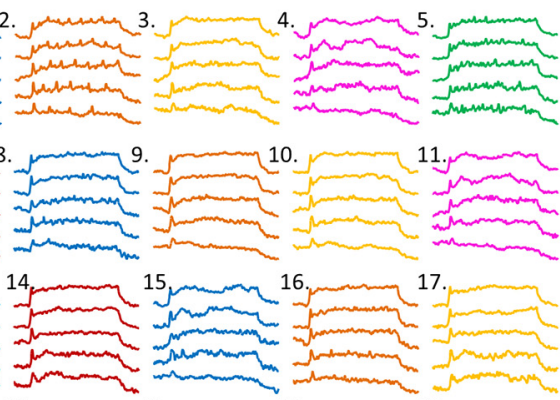

20.
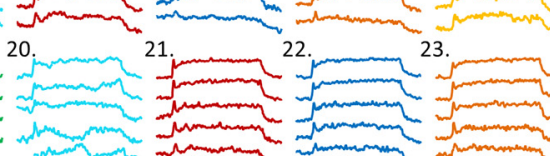

(n)
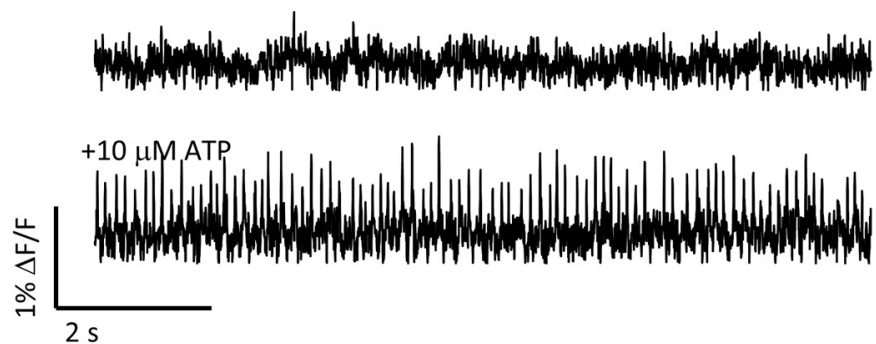

C
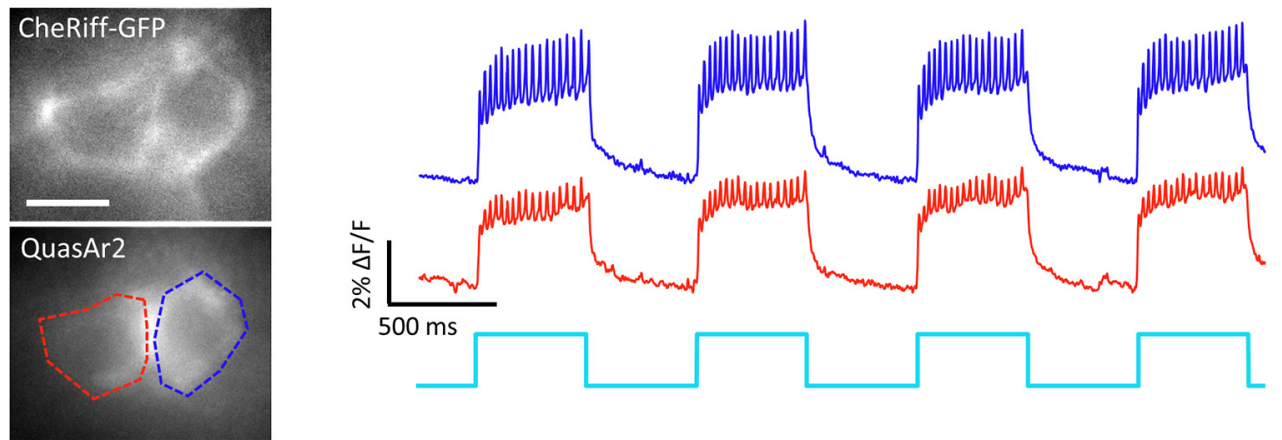

D
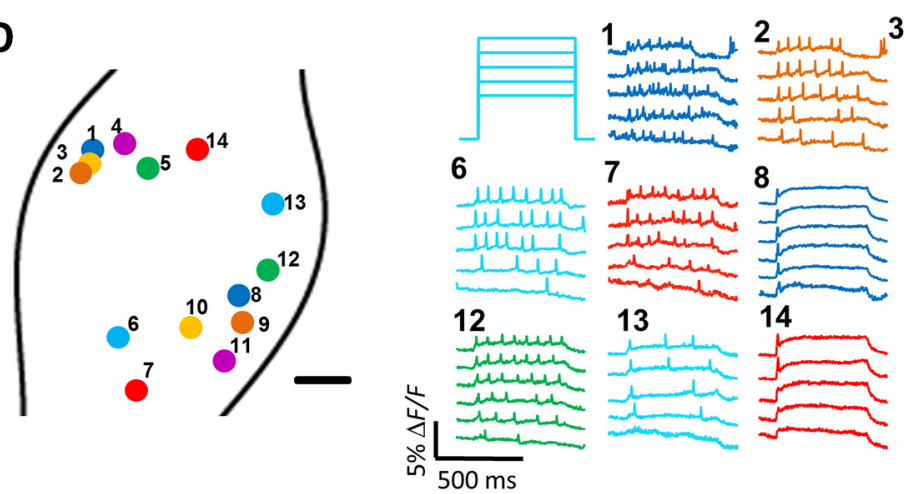

3

4

5

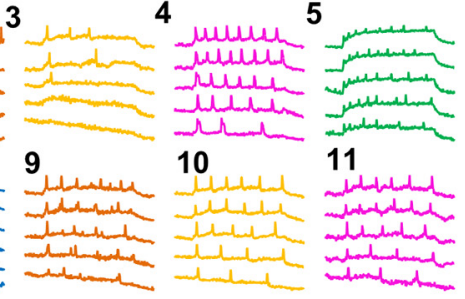

Figure 7. Optopatch imaging of mouse nodose ganglia ex vivo and in vivo. A, Exvivo wide-field recording in a nodose ganglion from P14 $\mathrm{Na}_{V} 1.8-$ Cre $^{+/-}$; Floxopatch $^{+/-}$mouse. Left, Wide-field epifluorescence images of CheRiff-eGFP. The bottom indicates the centers of the 23 cells recorded simultaneously. Scale bar, $10 \mu \mathrm{m}$. Right, Optically evoked activity of 23 cells. Blue stimulus intensities increased stepwise from $600 \mathrm{~mW} / \mathrm{cm}^{2}$ to $3 \mathrm{~W} / \mathrm{cm}^{2}$ (top left). QuasAr2 fluorescence was excited with red light at $300 \mathrm{~W} / \mathrm{cm}^{2}$. B, ATP-invoked firing of a neuron in the nodose ganglion. Left, Epifluorescence image of QuasAr2 expression. The recorded cell is shown with an asterisk. Scale bar, $10 \mu \mathrm{m}$. Right, QuasAr2 fluorescence before (top) and after (bottom) the addition of $10 \mu \mathrm{m}$ ATP. ATP induced rapid tonic firing that persisted for several minutes. C, Left, In vivo epifluorescence images of the Optopatch components in an intact nodose ganglion from a P58 $\mathrm{Na}_{v} 1.8-\mathrm{Cre}^{+/-} ;$Floxopatch ${ }^{+/+}$mouse. Scale bar, $10 \mu \mathrm{m}$. Right, Fluorescence recordings from the indicated cells under optical stimulation at blue intensity $500 \mathrm{~mW} / \mathrm{cm}^{2}$. D, Sequential Optopatch recordings from 14 nodose ganglion neurons in vivo. Left, Diagram showing locations of all the neurons recorded. Scale bar, $100 \mu \mathrm{m}$. Right, Fluorescence recordings of single cells under optical stimulation at blue intensities from 30 to $50 \mathrm{~mW} / \mathrm{cm}^{2}$. 
kayne et al., 2000; Taylor-Clark and Undem, 2006). We observed ATP-dependent increases in spontaneous firing (Fig. 7B).

We then imaged the nodose ganglia in adult anesthetized mice using $\mathrm{Na}_{V} 1.8$-Cre to drive expression and a preparation in which the still-attached ganglion was positioned between two coverslips (see Materials and Methods). To improve SNR, the cells were imaged at high magnification $(60 \times)$ with QuasAr2 excitation (40 $\mathrm{mW}$ ) focused to a region $40 \mu \mathrm{m}$ on a side. Typically, one or two neurons resided in each visual field. GFP and QuasAr2 fluorescence could easily be visualized (Fig. 7C). QuasAr2 fluorescence traces showed single action potentials upon CheRiff activation. We recorded optically induced spiking patterns with SNR $9.5 \pm$ 3.8 (mean \pm SD, $n=14$ cells; Fig. $7 D$ ). The cells showed a variety of optically induced spiking patterns, including tonic firing, bursting, and fast adaptation.

\section{Discussion}

The Floxopatch mice provide a broadly applicable tool for optical electrophysiology studies in excitable cells. The results here demonstrate feasibility of Optopatch measurements in acute brain slices and peripheral nerves in vivo. The ability to pair optogenetic stimulation with functional recording is particularly important in brain slices, where spontaneous activity is often low and sensory-evoked stimulus is not an option. Although other GEVIs have been demonstrated in mouse CNS in vivo, only the Archaerhodopsin-derived GEVIs are sufficiently red shifted for pairing with optogenetic stimulation.

Recent progress in protein engineering has led to a profusion of GEVIs with different tradeoffs in speed, voltage sensitivity, linearity, brightness, and trafficking efficiency (for recent reviews, see St-Pierre et al., 2015; Lin and Schnitzer, 2016). Voltage imaging in mouse brain in vivo has been demonstrated recently (Gong et al., 2015) using a GEVI called Ace-mNeon that functions via electrochromic FRET (Gong et al., 2014; Zou et al., 2014). This GEVI is excited with blue light $(\sim 488 \mathrm{~nm})$ and requires expression via a rabies virus. Another fast GFP-based GEVI, ASAP2f, was used recently to investigate subcellular voltage dynamics in flies using two-photon imaging (Yang et al., 2016). All known optogenetic actuators - even the most redshifted ones-retain $20-30 \%$ activation in the blue part of the spectrum used to excite Ace-mNeon or ASAP2f (Venkatachalam and Cohen, 2014). Therefore, spurious optogenetic activation by imaging light presents an obstacle to pairing of GFP-like GEVIs with an optogenetic actuator.

A transgenic GEVI mouse expressing Cre-dependent VSFP Butterfly 2.1 has been reported recently (Empson et al., 2015; Madisen et al., 2015). The good brightness of this reporter facilitated wide-field mapping of regions of cortical activation through a thinned skull preparation in vivo, but these mice have not yet yielded robust evidence of single-trial, single-spike sensitivity. The broad spectral band required for fluorescence excitation and imaging of this FRET-based GEVI renders it incompatible with optogenetic stimulation.

The low brightness of rhodopsin-based reporters created doubt about their applicability to 1-photon measurements in tissue or in vivo. However, the difference in excitation wavelength between GFP-based reporters (typically $488 \mathrm{~nm}$ ) and Arch-based reporters $(640 \mathrm{~nm})$ largely compensated for the lower brightness of the latter for applications in tissue (Deliolanis et al., 2008). Here, we showed a $>100$-fold decrease in tissue autofluorescence upon moving to the longer wavelength. Others have shown that, compared with $488 \mathrm{~nm}$, at $640 \mathrm{~nm}$, brain tissue shows $>50 \%$ greater scattering length (Yaroslavsky et al., 2002). Wäldchen et al. (2015) reported recently that, when mammalian cells were illuminated for $240 \mathrm{~s}$ at $200 \mathrm{~W} / \mathrm{cm}^{2}, 488 \mathrm{~nm}$ wavelength, $100 \%$ of cells either died or were "frozen." Repeating the experiment at 30 -fold greater intensity $\left(5.9 \mathrm{~kW} / \mathrm{cm}^{2}\right)$ at $640 \mathrm{~nm}$ wavelength led to no detectable cell death, implying far less than 1/30th the photochemical toxicity at the red wavelength.

Laser heating is the primary concern for imaging Archaerhodopsin-derived GEVIs in tissue. Recent studies have studied optical heating of brain tissue with either $532 \mathrm{~nm}$ visible light delivered through an optical fiber (Stujenske et al., 2015) or with near-infrared light used in two-photon microscopy (Podgorski and Ranganathan, 2016). Compared with $532 \mathrm{~nm}$, at 640 $\mathrm{nm}$, brain tissue shows an $\sim 14$-fold lower optical absorption and thus lower tissue heating (Jacques, 2013). We scaled the results in each of these works to $640 \mathrm{~nm}$ light focused onto a $50-\mu \mathrm{m}$ diameter spot and found that both predicted a temperature coefficient of $\sim 0.03^{\circ} \mathrm{C} / \mathrm{mW}$. We also performed Monte Carlo simulations of $640 \mathrm{~nm}$ photon propagation through tissue, coupled with simulations of thermal diffusion (ignoring convective dissipation from blood flow). For a diffraction-limited focal spot at a depth of $50 \mu \mathrm{m}$, the steady-state temperature coefficient was $0.04^{\circ} \mathrm{C} / \mathrm{mW}$ and, for a $50 \mu \mathrm{m}$ focus, we calculated $0.016^{\circ} \mathrm{C} / \mathrm{mW}$. These calculations are in broad agreement with the estimates based on literature simulations and data. Therefore, to keep the steady-state temperature rise at $<2^{\circ} \mathrm{C}$, the laser power should be limited to $<60 \mathrm{~mW}$. Our experiments were performed with no more than $40 \mathrm{~mW}$ of laser power.

The thermal simulations showed that it takes several seconds for the temperature rise to reach steady state. In a pulsed measurement, one can go to much higher illumination intensities while maintaining a safe temperature provided that the pulse duration is kept short. Because thermal damage is governed by the maximum temperature rise, pulsed measurements are an attractive strategy for imaging at higher laser power; one must simply leave enough time for the sample to cool between pulses. This approach is only viable when heating is the primary mechanism of photodamage; photochemical toxicity from blue light is cumulative, so there is no benefit to pulsing the measurement.

The primary biological challenge in using the Floxopatch mouse in CNS in vivo is the lower mean expression level compared with what can be achieved via viral gene delivery coupled with the already dim fluorescence of QuasAr2. Whereas virally delivered Optopatch shows signals in CNS in vivo, side-by-side comparisons of virally infected and transgenic acute brain slices indicated that the lower SNR of the transgenic measurements would be prohibitive for most in vivo CNS measurements. Recent work has shown that expression levels of transgenes in the TIGRE locus are comparable to virally expressed genes (Madisen et al., 2015), so this locus is a promising target for future transgenesis efforts.

New microscope designs will also be needed to achieve the full potential of the Floxopatch mouse and other GEVIs in vivo. Although two-photon microscopy has become a powerful technique for $\mathrm{Ca}^{2+}$ imaging in vivo, the technique does not readily extrapolate to voltage imaging. The challenges are that the $\sim 100$ fold greater speed required for voltage imaging, combined with the $\sim 100$-fold smaller detection volume (plasma membrane vs cytoplasm), require excitation rates per molecule that are associated with rapid photobleaching under two-photon illumination (Brinks et al., 2015). Furthermore, conventional galvo-based scanners have difficulty achieving the $\sim 1 \mathrm{kHz}$ frame rate needed for voltage imaging. Structured illumination and adaptive optics provide alternate approaches to optical sectioning with one- 
photon excitation. To minimize total optical power into the sample, one can contemplate schemes that focus illumination selectively on the membrane while avoiding interstitial regions. Improvements in microscopy could lead to advances just as significant as the recent advances in GEVI design.

Spatially and genetically resolved measures of single-cell excitability are an important component of efforts to model circuitlevel brain function. Although much recent effort has focused on structural and molecular aspects of circuit mapping (Macosko et al., 2015; Markram et al., 2015; Okaty et al., 2015), to understand function, one must also know the input-output properties of the individual neurons, which can often be strikingly different between morphologically and genetically similar cells (Dougherty et al., 2013; Giocomo, 2015). Recent large-scale patch-clamp efforts found important electrophysiological variability within neurons marked by the same nominal cell-type-specific promoter (Markram et al., 2015).

In comparing neuronal firing patterns evoked by manual patch clamp versus optogenetic stimulation, one must keep in mind that these two modalities deliver different kinds of stimuli: electrical stimulation is typically provided via current injection in current-clamp mode, whereas channelrhodopsins are conductances with reversal potential of $\sim 0 \mathrm{mV}$. In current-clamp stimulation, the injected current is independent of membrane voltage; in optogenetic stimulation, the magnitude of the current drops as the cell depolarizes and reverses sign for positive membrane voltages. These differences can lead to qualitatively different firing patterns in the same cell. AMPA receptors have a reversal potential of $\sim 0 \mathrm{mV}$, so optogenetic stimulation better mimics synaptic input than does current injection from a patch pipette.

A natural extension of the work described here will be to relate the optically evoked firing patterns to pharmacology, sensory evoked firing patterns, and to genetic and histochemical analysis of neuronal subtypes. For example, the $\mathrm{Na}_{\mathrm{V}} 1.8$ sodium channel is TTX resistant, so we anticipate that driving Optopatch expression via $\mathrm{Na}_{V} 1.8$-Cre will target TTX-resistant unmyelinated C-fibers preferentially. Measurements in the presence of TTX might thereby isolate pharmacologically the role of $\mathrm{Na}_{\mathrm{V}} 1.8$ in action potential generation. Optopatch measurements in somatosensory neurons in vivo may also help to decode the internal representations of physiological and environmental signals. Comparisons between optically evoked and naturalistic activation may reveal how and where the sensory encoding arises as the signal propagates from sensory terminals to the sensory ganglion and then on to the CNS. Transcriptional profiling of neurons that mediate particular sensory modalities may identify novel sensory proteins.

We have focused here on the PNS and CNS, but the Floxopatch mouse may also find application in studies on a variety of other cell types. Particularly exciting is the prospect of application in cells that have been challenging or impossible to access via conventional patch clamp, such as immune cells, pancreatic $\beta$ cells, and specialized sensory structures such as Merkel cells and Pacinian and Meissner's corpuscles. Patch-clamp experiments that have traditionally been the domain of highly skilled electrophysiologists could now become accessible to other researchers.

\section{Notes}

Supplemental material for this article is available at http://cohenweb.rc. fas.harvard.edu/Publications/Floxopatch_supplement_2016.pdf. Provided are supplemental figures and discussion on the specificity and selectivity of Optopatch expression, the effect of whole-body Optopatch expression, the optical properties of acute brain slices, depth-dependent signal levels in acute brain slices, and characterization of red-lightinduced heating of tissue. This material has not been peer reviewed.

\section{References}

Abraira VE, Ginty DD (2013) The sensory neurons of touch. Neuron 79: 618-639. CrossRef Medline

Agarwal N, Offermanns S, Kuner R (2004) Conditional gene deletion in primary nociceptive neurons of trigeminal ganglia and dorsal root ganglia. Genesis 38:122-129. CrossRef Medline

Berthoud HR, Neuhuber WL (2000) Functional and chemical anatomy of the afferent vagal system. Auton Neurosci 85:1-17. CrossRef Medline

Boyden ES, Zhang F, Bamberg E, Nagel G, Deisseroth K (2005) Millisecondtimescale, genetically targeted optical control of neural activity. Nat Neurosci 8:1263-1268. CrossRef Medline

Brinks D, Klein AJ, Cohen AE (2015) Two-photon fluorescence lifetime imaging microscopy (2P-FLIM) of genetically encoded voltage indicators as a probe of absolute membrane voltage. Biophys J 109:914-921. CrossRef Medline

Carrillo-Reid L, Yang W, Bando Y, Peterka DS, Yuste R (2016) Imprinting and recalling cortical ensembles. Science 353:691-694. CrossRef Medline

Chiu IM, Barrett LB, Williams EK, Strochlic DE, Lee S, Weyer AD, Lou S, Bryman GS, Roberson DP, Ghasemlou N, Piccoli C, Ahat E, Wang V, Cobos EJ, Stucky CL, Ma Q, Liberles SD, Woolf CJ (2014) Transcriptional profiling at whole population and single cell levels reveals somatosensory neuron molecular diversity. ELife 3:e04660. CrossRef Medline

Cockayne DA, Hamilton SG, Zhu QM, Dunn PM, Zhong Y, Novakovic S, Malmberg AB, Cain G, Berson A, Kassotakis L, Hedley L, Lachnit WG, Burnstock G, McMahon SB, Ford AP (2000) Urinary bladder hyporeflexia and reduced pain-related behaviour in P2X3-deficient mice. Nature 407:1011-1015. CrossRef Medline

Deliolanis NC, Kasmieh R, Wurdinger T, Tannous BA, Shah K, Ntziachristos V (2008) Performance of the red-shifted fluorescent proteins in deeptissue molecular imaging applications. J Biomed Opt 13:044008. CrossRef Medline

Dougherty KA, Nicholson DA, Diaz L, Buss EW, Neuman KM, Chetkovich DM, Johnston D (2013) Differential expression of HCN subunits alters voltage-dependent gating of h-channels in CA1 pyramidal neurons from dorsal and ventral hippocampus. J Neurophysiol 109:1940-1953. CrossRef Medline

Dragatsis I, Zeitlin S (2000) CaMKII-cre transgene expression and recombination patterns in the mouse brain. Genesis 26:133-135. CrossRef Medline

Empson RM, Goulton C, Scholtz D, Gallero-Salas Y, Zeng H, Knöpfel T (2015) Validation of optical voltage reporting by the genetically encoded voltage indicator VSFP butterfly from cortical layer $2 / 3$ pyramidal neurons in mouse brain slices. Physiol Rep 3: pii: e12468. CrossRef Medline

Gautron L, Sakata I, Udit S, Zigman JM, Wood JN, Elmquist JK (2011) Genetic tracing of $\mathrm{Na}_{\mathrm{V}} 1.8$-expressing vagal afferents in the mouse. J Comp Neurol 519:3085-3101. CrossRef Medline

Gentet LJ, Kremer Y, Taniguchi H, Huang ZJ, Staiger JF, Petersen CC (2012) Unique functional properties of somatostatin-expressing GABAergic neurons in mouse barrel cortex. Nat Neurosci 15:607-612. CrossRef Medline

Giocomo LM (2015) Large scale in vivo recordings to study neuronal biophysics. Curr Opin Neurobiol 32:1-7. CrossRef Medline

Gong S, Doughty M, Harbaugh CR, Cummins A, Hatten ME, Heintz N, Gerfen CR (2007) Targeting cre recombinase to specific neuron populations with bacterial artificial chromosome constructs. J Neurosci 27: 9817-9823. CrossRef Medline

Gong Y, Wagner MJ, Zhong Li J, Schnitzer MJ (2014) Imaging neural spiking in brain tissue using FRET-opsin protein voltage sensors. Nat Commun 5:3674. CrossRef Medline

Gong Y, Huang C, Li JZ, Grewe BF, Zhang Y, Eismann S, Schnitzer MJ (2015) High-speed recording of neural spikes in awake mice and flies with a fluorescent voltage sensor. Science 350:1361-1366. CrossRef Medline

Harris JA, Hirokawa KE, Sorensen SA, Gu H, Mills M, Ng LL, Bohn P, Mortrud M, Ouellette B, Kidney J, Smith KA, Dang C, Sunkin S, Bernard A, Oh SW, Madisen L, Zeng H (2014) Anatomical characterization of cre driver mice for neural circuit mapping and manipulation. Front Neural Circuits 8:76. CrossRef Medline

Hochbaum DR et al. (2014) All-optical electrophysiology in mammalian 
neurons using engineered microbial rhodopsins. Nat Methods 11:825833. CrossRef Medline

Jacques SL (2013) Optical properties of biological tissues: a review. Phys Med Biol 58:R37-R61. CrossRef Medline

Kowalski J, Gan J, Jonas P, Pernía-Andrade AJ (2016) Intrinsic membrane properties determine hippocampal differential firing pattern in vivo in anesthetized rats. Hippocampus 26:668-682. CrossRef Medline

Kralj JM, Douglass AD, Hochbaum DR, Maclaurin D, Cohen AE (2012) Optical recording of action potentials in mammalian neurons using a microbial rhodopsin. Nat Methods 9:90-95. CrossRef Medline

Han L, Ma C, Liu Q, Weng HJ, Cui Y, Tang Z, Kim Y, Nie H, Qu L, Patel KN, Li Z, McNeil B, He S, Guan Y, Xiao B, Lamotte RH, Dong X (2012) A subpopulation of nociceptors specifically linked to itch. Nat Neurosci 16:174-182. CrossRef Medline

Lin MZ, Schnitzer MJ (2016) Genetically encoded indicators of neuronal activity. Nat Neurosci 19:1142-1153. CrossRef Medline

Liu Y, Ma Q (2011) Generation of somatic sensory neuron diversity and implications on sensory coding. Curr Opin Neurobiol 21:52-60. CrossRef Medline

Looger LL, Griesbeck O (2012) Genetically encoded neural activity indicators. Curr Opin Neurobiol 22:18-23. CrossRef Medline

Ma Y, Hu H, Berrebi AS, Mathers PH, Agmon A (2006) Distinct subtypes of somatostatin-containing neocortical interneurons revealed in transgenic mice. J Neurosci 26:5069-5082. CrossRef Medline

Macosko EZ, Basu A, Satija R, Nemesh J, Shekhar K, Goldman M, Tirosh I, Bialas AR, Kamitaki N, Martersteck EM, Trombetta JJ, Weitz DA, Sanes JR, Shalek AK, Regev A, McCarroll SA (2015) Highly parallel genomewide expression profiling of individual cells using nanoliter droplets. Cell 161:1202-1214. CrossRef Medline

Madisen L, Zwingman TA, Sunkin SM, Oh SW, Zariwala HA, Gu H, Ng LL, Palmiter RD, Hawrylycz MJ, Jones AR, Lein ES, Zeng H (2010) A robust and high-throughput cre reporting and characterization system for the whole mouse brain. Nat Neurosci 13:133-140. CrossRef Medline

Madisen L et al. (2012) A toolbox of cre-dependent optogenetic transgenic mice for light-induced activation and silencing. Nat Neurosci 15:793802. CrossRef Medline

Madisen L et al. (2015) Transgenic mice for intersectional targeting of neural sensors and effectors with high specificity and performance. Neuron 85:942-958. CrossRef Medline

Malin SA, Davis BM, Molliver DC (2007) Production of dissociated sensory neuron cultures and considerations for their use in studying neuronal function and plasticity. Nat Protoc 2:152-160. CrossRef Medline

Markram H et al. (2015) Reconstruction and simulation of neocortical microcircuitry. Cell 163:456-492. CrossRef Medline

Mukamel EA, Nimmerjahn A, Schnitzer MJ (2009) Automated analysis of cellular signals from large-scale calcium imaging data. Neuron 63:747760. CrossRef Medline

Niwa H, Yamamura K, Miyazaki J (1991) Efficient selection for highexpression transfectants with a novel eukaryotic vector. Gene 108:193199. CrossRef Medline

Okaty BW, Freret ME, Rood BD, Brust RD, Hennessy ML, deBairos D, Kim JC, Cook MN, Dymecki SM (2015) Multi-scale molecular deconstruction of the serotonin neuron system. Neuron 88:774-791. CrossRef Medline

Packer AM, Russell LE, Dalgleish HW, Häusser M (2015) Simultaneous alloptical manipulation and recording of neural circuit activity with cellular resolution in vivo. Nat Methods 12:140-146. CrossRef Medline

Podgorski K, Ranganathan G (2016) Brain heating induced by nearinfrared lasers during multiphoton microscopy. J Neurophysiol 116: 1012-1023. CrossRef Medline

Price J (1985) An lmmunohistochemical and quantitative examination of dorsal root ganglion neuronal subpopulations. J Neurosci 5:2051-2059. Medline

Qiao GF, Yang BF, Li WH, Li BY (2003) Effects of artemisinin on action potentials from C-type nodose ganglion neurons. Acta Pharmacol Sin 24:937-942. Medline

Rickgauer JP, Deisseroth K, Tank DW (2014) Simultaneous cellularresolution optical perturbation and imaging of place cell firing fields. Nat Neurosci 17:1816-1824. CrossRef Medline

Shaner NC, Lin MZ, McKeown MR, Steinbach PA, Hazelwood KL, Davidson MW, Tsien RY (2008) Improving the photostability of bright monomeric orange and red fluorescent proteins. Nat Methods 5:545-551. CrossRef Medline

Stansfeld CE, Wallis DI (1985) Properties of visceral primary afferent neurons in the nodose ganglion of the rabbit. J Neurophysiol 54:245-260. Medline

Stirling LC, Forlani G, Baker MD, Wood JN, Matthews EA, Dickenson AH, Nassar MA (2005) Nociceptor-specific gene deletion using heterozygous $\mathrm{Na}_{\mathrm{V}} 1.8$-cre recombinase mice. Pain 113:27-36. CrossRef Medline

St-Pierre F, Chavarha M, Lin MZ (2015) Designs and sensing mechanisms of genetically encoded fluorescent voltage indicators. Curr Opin Chem Biol 27:31-38. CrossRef Medline

Stujenske JM, Spellman T, Gordon JA (2015) Modeling the spatiotemporal dynamics of light and heat propagation for in vivo optogenetics. Cell Reports 12:525-534. CrossRef Medline

Taylor-Clark T, Undem BJ (2006) Transduction mechanisms in airway sensory nerves. J Appl Physiol 101:950-959. Medline

Urban-Ciecko J, Fanselow EE, Barth AL (2015) Neocortical somatostatin neurons reversibly silence excitatory transmission via GABAb receptors. Curr Biol 25:722-731. CrossRef Medline

Usoskin D, Furlan A, Islam S, Abdo H, Lönnerberg P, Lou D, Hjerling-Leffler J, Haeggström J, Kharchenko O, Kharchenko PV, Linnarsson S, Ernfors P (2015) Unbiased classification of sensory neuron types by large-scale single-cell RNA sequencing. Nat Neurosci 18:145-153. CrossRef Medline van Aerde KI, Feldmeyer D (2015) Morphological and physiological characterization of pyramidal neuron subtypes in rat medial prefrontal cortex. Cereb Cortex 25:788-805. CrossRef Medline

Venkatachalam V, Cohen AE (2014) Imaging GFP-based reporters in neurons with multiwavelength optogenetic control. Biophys J 107:15541563. CrossRef Medline

Wäldchen S, Lehmann J, Klein T, van de Linde S, Sauer M (2015) Lightinduced cell damage in live-cell super-resolution microscopy. Sci Rep 5:15348. CrossRef Medline

Williams EK, Chang RB, Strochlic DE, Umans BD, Lowell BB, Liberles SD (2016) Sensory neurons that detect stretch and nutrients in the digestive system. Cell in press:

Yang HH, St-Pierre F, Sun X, Ding X, Lin MZ, Clandinin TR (2016) Subcellular imaging of voltage and calcium signals reveals neural processing in vivo. Cell 166:245-257. CrossRef Medline

Yaroslavsky AN, Schulze PC, Yaroslavsky IV, Schober R, Ulrich F, Schwarzmaier HJ (2002) Optical properties of selected native and coagulated human brain tissues in vitro in the visible and near infrared spectral range. Phys Med Biol 47:2059-2073. CrossRef Medline

Zacharová G, Palecek J (2009) Parvalbumin and TRPV1 receptor expression in dorsal root ga Palecek nglion neurons after acute peripheral inflammation. Physiol Res 58:305-309. Medline

Zariwala HA, Borghuis BG, Hoogland TM, Madisen L, Tian L, De Zeeuw CI, Zeng H, Looger LL, Svoboda K, Chen TW (2012) A cre-dependent GCaMP3 reporter mouse for neuronal imaging in vivo. J Neurosci 32: 3131-3141. CrossRef Medline

Zheng JH, Walters ET, Song XJ (2007) Dissociation of dorsal root ganglion neurons induces hyperexcitability that is maintained by increased responsiveness to cAMP and cGMP. J Neurophysiol 97:15-25. CrossRef Medline

Zou P, Zhao Y, Douglass AD, Hochbaum DR, Brinks D, Werley CA, Harrison DJ, Campbell RE, Cohen AE (2014) Bright and fast multicoloured voltage reporters via electrochromic FRET. Nat Commun 5:4625. CrossRef Medline 